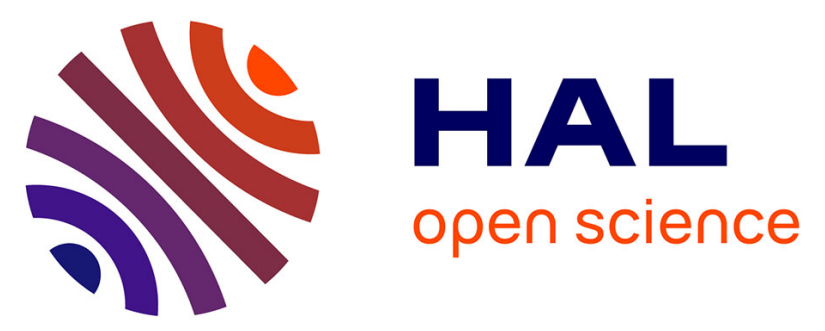

\title{
Multi-criteria framework as an innovative tradeoff approach to determine the shelf-life of high pressure-treated poultry
}

Sandrine Guillou, Marion Lerasle, Hélène Simonin, V. Anthoine, R. Chéret, Michel M. Federighi, J.-M. Membré

\section{To cite this version:}

Sandrine Guillou, Marion Lerasle, Hélène Simonin, V. Anthoine, R. Chéret, et al.. Multicriteria framework as an innovative tradeoff approach to determine the shelf-life of high pressure-treated poultry. International Journal of Food Microbiology, 2016, 233, pp.60 - 72. 10.1016/j.ijfoodmicro.2016.05.027 . hal-01485162

\section{HAL Id: hal-01485162 \\ https://u-bourgogne.hal.science/hal-01485162}

Submitted on 27 May 2020

HAL is a multi-disciplinary open access archive for the deposit and dissemination of scientific research documents, whether they are published or not. The documents may come from teaching and research institutions in France or abroad, or from public or private research centers.
L'archive ouverte pluridisciplinaire HAL, est destinée au dépôt et à la diffusion de documents scientifiques de niveau recherche, publiés ou non, émanant des établissements d'enseignement et de recherche français ou étrangers, des laboratoires publics ou privés. 


\title{
Multi-criteria framework as an innovative tradeoff approach to determine the shelf-life of high pressure-treated poultry
}

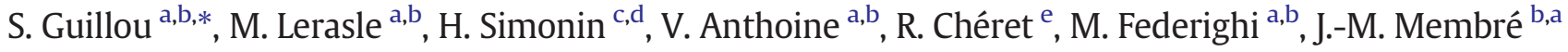 \\ a Lunam Université, Oniris, Nantes, France \\ b INRA, UMR1014, SECALIM, Nantes, France \\ c UMR Procédés Alimentaires et Microbiologiques, équipe PBM, Université de Bourgogne, Agrosup Dijon, France \\ d Université de Bourgogne, Dijon, France \\ e CTCPA, Nantes, France
}

\section{A R T I C L E I N F O}

\section{Article history:}

Received 17 July 2015

Received in revised form 11 March 2016

Accepted 29 May 2016

Available online 14 June 2016

\section{Keywords:}

Risk-risk trade-off

Lactate

Food hygiene

Food safety

Sensorial quality

\begin{abstract}
A B S T R A C T
A multi-criteria framework combining safety, hygiene and sensorial quality was developed to investigate the possibility of extending the shelf-life and/or removing lactate by applying High Hydrostatic Pressure (HHP) in a ready-to-cook (RTC) poultry product. For this purpose, Salmonella and Listeria monocytogenes were considered as safety indicators and Escherichia coli as hygienic indicator. Predictive modeling was used to determine the influence of HHP and lactate concentration on microbial growth and survival of these indicators. To that end, probabilistic assessment exposure models developed in a previous study (Lerasle, M., Guillou, S., Simonin, H., Anthoine, V., Chéret, R., Federighi, M., Membré, J.M. 2014. Assessment of Salmonella and L. monocytogenes level in ready-to-cook poultry meat: Effect of various high pressure treatments and potassium lactate concentrations. International Journal of Food Microbiology 186, 74-83) were used for L. monocytogenes and Salmonella. Besides, for E. coli, an exposure assessment model was built by modeling data from challenge-test experiments. Finally, sensory tests and color measurements were performed to evaluate the effect of HHP on the organoleptic quality of an RTC product. Quantitative rules of decision based on safety, hygienic and organoleptic criteria were set. Hygienic and safety criteria were associated with probability to exceed maximum contamination levels of $L$. monocytogenes, Salmonella and E. coli at the end of the shelf-life whereas organoleptic criteria corresponded to absence of statistical difference between pressurized and unpressurized products. A tradeoff between safety and hygienic risk, color and taste, was then applied to define process and formulation enabling shelf-life extension. In the resulting operating window, one condition was experimentally assayed on naturally contaminated RTC products to validate the multi-criteria approach. As a conclusion, the framework was validated; it was possible to extend the shelf-life of an RTC poultry product containing $1.8 \%(w / w)$ lactate by one week, despite slight color alteration. This approach could be profitably implemented by food processors as a decision support tool for shelf-life determination.
\end{abstract}

(C) 2016 Elsevier B.V. All rights reserved

\section{Introduction}

Poultry meat is highly perishable as spoilage in raw chicken may occur within a couple of weeks following slaughtering, under refrigerated storage (Lin et al., 2004). Further steps like mincing and mixing, currently used for some processing ready-to-cook (RTC) poultry products even more shorten the shelf-life.

During the entire shelf-life, food products have to be safe and guaranteed for a defined and acceptable quality under expected (or specified) conditions of distribution and storage. Shelf-life determination of

\footnotetext{
* Corresponding author at: UMR1014 SECALIM, Oniris, Route de Gachet, CS 40706, F44307 Nantes cedex 03, France.

E-mail address: sandrine.guillou@oniris-nantes.fr (S. Guillou).
}

RTC products is an important issue for food manufacturers since they have to address the market constraints for longer shelf- life, the need for safety required by regulations and the need for quality required by consumers. For this purpose, they have to comply with legal requirements, i.e. i) safety and ii) hygienic criteria (Directive 2000/13/EC and Regulation 2073/2005) but also with iii) organoleptic considerations (FAO/WHO, 2004). They usually do experimental challenge-tests but do not use quantitative tools on a regular basis, except maybe for assessing compliance with safety criteria where predictive microbiology software is available. In the literature dealing with shelf-life extension or determination, there is no quantitative assessment based upon a multi-criteria framework combining the three above criteria. For example, Pereira et al. (2015) evaluated the shelf-life of sliced Portuguese traditional blood sausage without the use of predictive modeling. In the 
approach followed by Mantilla et al. (2012), the influence of gamma-irradiation on the shelf-life of poultry breast fillets conditioned under modified atmosphere was investigated by successively considering the time-to-reach $7 \mathrm{log} \mathrm{cfu} / \mathrm{g}$ heterotrophic aerobic mesophilic bacteria and the detrimental effects of the treatment on color and sensory aspects. The only study applying multi-criteria framework to food microbiology, dealt with foodborne risks by considering health, social and market impacts in the objective of prioritization of foodborne risks (Ruzante et al., 2010).

The increasing consumer demand for healthier formulations of meat products, results in a strong tendency of reducing and even removing preservatives and additives in food, such as lactate (Wilcock et al., 2004). High hydrostatic pressure (HHP) represents an innovative alternative approach likely to be used to offset reduction of preservatives. It enables inactivation of foodborne pathogens and spoilage microorganisms while limiting detrimental effects on nutritional and organoleptic qualities of food (Hayman et al., 2004; Patterson, 2005; Simonin et al., 2012).

In a previous study, a HHP treatment step added in an existing process was shown to improve the safety of an RTC poultry product (Lerasle et al., 2014). It enabled the build-up of exposure assessment models associated with Listeria monocytogenes and Salmonella in an RTC HHPprocessed poultry product. The objective of the present study was, with the same product and process, to investigate the possibility of extending the shelf-life and/or removing lactate from the current product formulation by applying HHP. For this purpose, a multi-criteria framework combining safety, hygienic and sensorial quality was developed, taking advantage of the models previously developed for $L$. monocytogenes and Salmonella to cover the safety part. Besides, challenge-tests were performed to build the exposure assessment model of Escherichia coli in an RTC HHP-processed poultry product associated with the hygienic part. Lastly, the third criterion associated with the organoleptic quality was determined by sensory analysis and color measurements. Combining the three domain-associated results, a tradeoff between quantitative safety, hygienic and sensorial criteria was developed for an extended shelf-life 1) to determine process parameters satisfying all criteria and 2) experimentally test a suitable HHP treatment in order 3 ) to ultimately validate the multi-criteria framework.

\section{Materials and methods}

\subsection{Overview of the multi-criteria framework}

The study was performed with the same product as in the previous study of Lerasle et al. (2014), i.e. RTC poultry meat composed with turkey meat (79\%), pork fat (11\%), spices $(<0.1 \%)$ and water $(10 \%)$ provided the day after packaging under modified atmosphere.

A multi-criteria framework combining safety $(\mathrm{S})$, hygienic $(\mathrm{H})$, and organoleptic criteria $(\mathrm{O})$ was used to determine the HHP parameters (pressure intensity and duration) necessary to fulfill the criteria defined below for an extended shelf-life (Fig. 1).

Salmonella and L. monocytogenes were selected as safety indicators (Lerasle et al., 2014) whereas E. coli, defined as a hygienic indicator by EU recommendation No. 2073/2005, was accordingly chosen as such for assessing the hygienic quality of the poultry product.

The three criteria were quantitative. The two first ones represented a maximum contamination level, at the end of the shelf-life of one or several selected microbial indicators: $\mathrm{N}_{\text {upperlimit }} \mathrm{N}_{\text {upperlimit }}$ could be assimilated to a PO (Performance Objective) set in the context of the food safety management framework by ICMSF (2002). The decision making associated to these two criteria consisted in determining the set of combinations of pressure intensity and duration enabling the minimization of these criteria below the set maximum levels, i.e. $\mathrm{N}_{\text {upperlimit }}$, with and without lactate addition (1.8\%). $\mathrm{N}_{\text {upperlimit }}$ was adapted from to microbiological criteria of the foodstuffs defined by the Commission Regulation (EC) No 2073/2005, i.e. $100 \mathrm{cfu} / \mathrm{g}$ for L. monocytogenes in ready-to-eat foods able to support its growth, and $0.04 \mathrm{cfu} / \mathrm{g}$ (absence in 25-g) in minced meat and meat preparations made from poultry meat intended to be eaten cooked for Salmonella, and $5000 \mathrm{cfu} / \mathrm{g}$ in meat preparations for E. coli.

The decision was derived from the distributions of the contamination levels. The notion of acceptable risk does not really exist for microbiological risk (Hunter and Fewtrell, 2001). However, in canned products, the rate of spoilage of one spore per 10,000 units is considered as a tolerable level (CCFRA, 1977). Hence in our study, it was considered that the risk of $1 / 10,000$ i.e. $0.01 \%$ that $E$. coli exceeds 5000 was reasonable whereas a more stringent criterion of $1 / 100,000$, i.e. $0.001 \%$ was chosen for the risk associated with safety criteria non compliance.

Hence criteria were fulfilled when:

$$
\begin{aligned}
& \mathrm{P}\left(\mathrm{N}_{\mathrm{SL}}<\mathrm{N}_{\text {upperlimit }}\right)>99.99 \% \text { for hygienic criteria, } \\
& \mathrm{P}\left(\mathrm{N}_{\mathrm{SL}}<\mathrm{N}_{\text {upperlimit }}\right)>99.999 \% \text { for safety criteria }
\end{aligned}
$$

The distributions of the contamination levels of Salmonella, $L$. monocytogenes and E. coli at the end of the shelf-life, $\mathrm{N}_{\mathrm{SL}}$, as a function of HHP and chilled storage conditions (treatment duration and intensity, lactate concentration, storage duration and temperature) were estimated by using exposure assessment models. For L. monocytogenes and Salmonella exposure assessment models previously built were used (Lerasle et al., 2014). Their modular structure included prevalence data of $100-\mathrm{kg}$ batches stored at $4{ }^{\circ} \mathrm{C}$ obtained from factories and influence of mixing, partitioning, HHP and chilled storage steps on RTC product contamination levels.

Regarding E. coli, the exposure assessment model had to be built by using new data: first, data from factories to determine the initial contamination level of E. coli in RTC products, second, experimental challenge-test data to model the influence of HHP and lactate concentration on the contamination level of E. coli, were generated.

Next, by running the probabilistic models, operational HHP process windows enabling respectively to fulfill safety criteria $(S)$ and hygienic criteria $(\mathrm{H})$ were drawn as a function of the shelf-life duration, lactate concentration and HHP conditions.

Besides, color measurements, sensory panel scores and a discrimination test were used to delimit an acceptable operational HHP process window (O). It was defined by HHP conditions that were shown not to produce significant change/damage of the product, which is generally performed in the case of new product development.

A risk-risk tradeoff framework was then conducted to examine the possibility of lactate removal from the current product formulation or at least to enable the extension of the current shelf-life in presence of lactate. Under the selected conditions, all resulting operational windows were superimposed to draw a restricted window for which all criteria were met.

Ultimately, a HHP treatment was then selected inside the resulting operational window for validation of the multi-criteria framework; the experiment was performed on naturally contaminated products.

\subsection{High pressure treatment}

Two-hundred gram meat samples were high pressure-treated in a 50-L horizontal high pressure pilot unit (ACB pressure system, Nantes, France) under the same conditions as previously described (Lerasle et al., 2014). The samples previously held at $4{ }^{\circ} \mathrm{C}$ during storage were inserted into the pressurizing chamber filled with water at $15 \pm 1{ }^{\circ} \mathrm{C}$ and exposed to HHP. During HHP treatment, the product temperature in the pressure chamber increased because of the adiabatic heating, without however exceeding $10.5^{\circ} \mathrm{C}$.

\subsection{Microbiological analyses}

For challenge-tests and validation experiments, samples were analyzed one day minimum at $4{ }^{\circ} \mathrm{C}$ after HHP, a period of time favoring the repair of injured cells before performing microbiological analyses. 


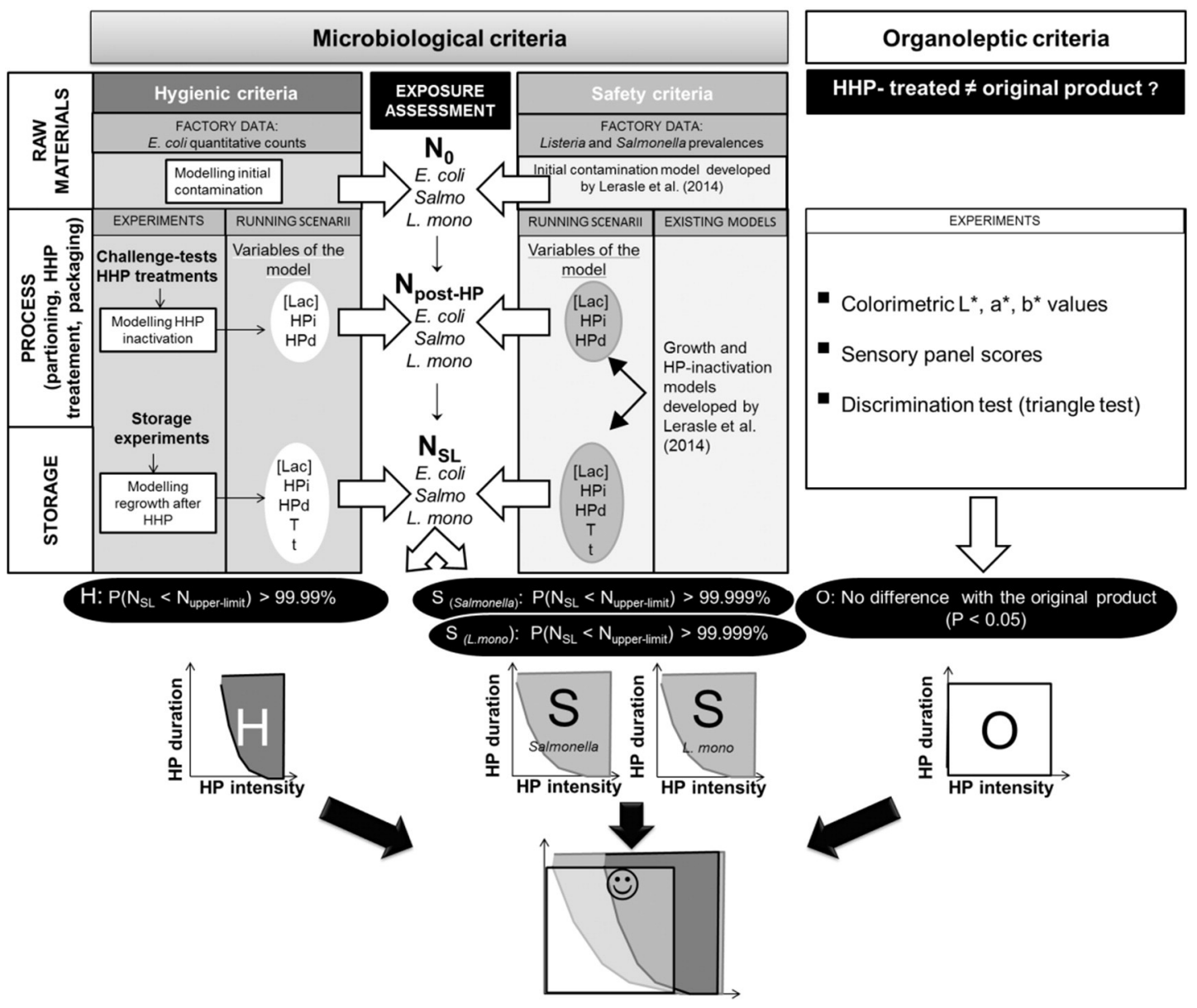

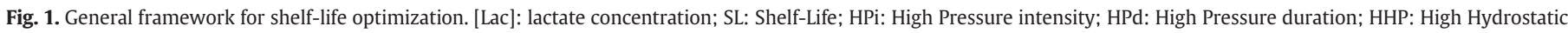
Pressure; S: Safety; H: Hygienic; O: Organoleptic.

For this purpose, $10 \mathrm{~g}$ of meat were withdrawn aseptically from the 200 -g portion and added to $90 \mathrm{~mL}$ sterile peptone water (Biokar, France) in a sterile plastic bag with a filter (Bagpage R, Interscience, France). After homogenization for $60 \mathrm{~s}$ in Stomacher blender (Bagmixer 400P, Interscience, France), serial dilutions in peptone water were spread in the appropriate culture medium in order to enumerate the targeted microbial flora.

In the challenge-tests study, E. coli was enumerated on pressurized and unpressurized samples one day after HHP and for each follow-up storage point (Section 2.4.2). E. coli counts were evaluated by pour plate technique with $1 \mathrm{~mL}$ of appropriate dilutions cultured on non-selective medium Tryptic Soy plus 0.6\% Yeast Extract count Agar (TSYEA, Oxoid). All plates were incubated at $37^{\circ} \mathrm{C}$ for $24 \mathrm{~h}$ in duplicate.

For validation experiments, E. coli, L. monocytogenes, Salmonella and lactic acid bacteria ( $\mathrm{LAB}$ ) were enumerated on the control at the current shelf-life of 15 days and on the pressurized product at two storage points beyond the current shelf-life. E. coli counts were evaluated by pour plate technique with $1 \mathrm{~mL}$ of appropriate dilutions and cultured on selective culture medium Tryptone Bile X glucuronide (TBX, Oxoid). All plates were incubated at $37^{\circ} \mathrm{C}$ for $24 \mathrm{~h}$ in duplicate. LAB counts were determined on Man Rogosa Sharp medium (MRS, Biokar). All plates were anaerobically incubated at $30{ }^{\circ} \mathrm{C}$ for $48 \mathrm{~h}$ in duplicate. Detection in $25 \mathrm{~g}$ and enumeration of $L$. monocytogenes were performed according the method ALOA One Day ${ }^{\circledR}$ AFNOR N ${ }^{\circ}$ AES 10/3-09/00 certified NF validation (NF EN ISO 11290). Detection in $25 \mathrm{~g}$ and enumeration of Salmonella were assayed by using the method IRIS $®$ AFNOR ${ }^{\circ}$ BKR 23/07-10/11 certified NF validation (NF EN ISO 6579). Quantitative results were expressed in log cfu/g of meat; the detection limit was $10 \mathrm{cfu} / \mathrm{g}$.

\subsection{Challenge-test experiments and prediction of E. coli contamination level}

In order to determine the contamination level of $E$. coli at the end of the shelf-life, a modular probabilistic model was built. The model was divided into as many modules as processing steps: i) reception of raw meat materials, mincing, mixing meat and spices into $100-\mathrm{kg}$ meat batches and then the addition of lactate, ii) partitioning and packaging into 200-g modified atmosphere packs, iii) high pressure treatment of the meat, and iv) storage in chilled conditions until the end of the shelf-life. The first two modules were built on data and knowledge from factories in France (Section 2.4.1.). On the other hand, the third and fourth modules were built using data from an experimental design carried out in our laboratory (Section 2.4.2.).

\subsubsection{Initial contamination level of $E$. coli}

The first step, "reception of raw meat materials" was built by applying the function fitdistcens (fit distribution package of R software) on 563 quantitative counts of $E$. coli collected from nine sampling campaigns in various factories (Delignette-Muller et al., 2014). The dataset included $15 \%$ of censored data. The best fit was obtained with the Normal distribution of the log counts.

\subsubsection{Contamination level of $E$. coli along the processing steps}

For the second step "mixing and partitioning into 200-g packs", the contamination level of the 200 -g meat pack, $\mathrm{N}_{200}$, was deduced from the level in the batch, by considering that the average storage duration of $1 \mathrm{~h}$ at $4{ }^{\circ} \mathrm{C}$ was not long enough to enable $E$. coli growth. The third and fourth steps "high pressure treatment of the meat" and "storage in 
chilled conditions until the end of the shelf-life" were both built using an experimental design carried out in our laboratory. Details are provided below.

The effect of HHP and potassium lactate on E. coli inactivation was evaluated according to a Latin square design $(4 \times 4)$ : pressure at 300 , 400, 450 and $500 \mathrm{MPa}$, holding time of 2, 6, 10 and $14 \mathrm{~min}$ and potassium lactate concentrations of $0,0.9,1.8$ or $2.7 \% w / w$ (Table 1 ).

Unpressurized inoculated meat samples with the formulation of the current product ( $1.8 \%(w / w)$ lactate) were considered as controls.

After HHP, samples intended for immediate influence of HHP were analyzed the next day $(t=1 \mathrm{~d})$. The other ones were held at $8{ }^{\circ} \mathrm{C}$ to monitor $E$. coli regrowth after $\operatorname{HHP}(t=6,7,9,12,14,16,19,22$ and 26 days). For each follow-up point during the 26 days of chilled storage, samples were withdrawn and microbiological analyses were performed. The temperature of $8{ }^{\circ} \mathrm{C}$ was chosen as the most cautious condition in favor of higher growth of $E$. coli. Because of high biological variability, the experimental design was duplicated, which increased the number of samples to 340 (320 high pressure-treated and 20 unpressurized samples used as controls). The duplicated plans were experimented at one week interval.

2.4.2.1. Escherichia coli strains and culture conditions. The three strains of E. coli (plt01, plt02, plt03) selected in this study had been isolated from poultry meat associated with non compliance with hygiene requirements
(EU recommendation No. 2073/2005). For each strain, $100 \mu \mathrm{L}$ of a stock culture stored in brain heart infusion (BHI, Biokar) containing 20\% glycerol at $-80^{\circ} \mathrm{C}$ was transferred on TSYEA and incubated at $37^{\circ} \mathrm{C}$ for $24 \mathrm{~h}$. For each strain, a loopful was transferred from the TSYEA plate to $50 \mathrm{~mL}$ of Tryptic Soy Broth (TSB, Oxoid). Cultures were then incubated at $37^{\circ} \mathrm{C}$ for $18 \mathrm{~h}$ under agitation until stationary phase and centrifuged at $4000 \mathrm{~g}$ at $4{ }^{\circ} \mathrm{C}$ for $10 \mathrm{~min}$. The pellets were resuspended in equivalent amounts of sterile physiological water and mixed to give the cocktail of three E. coli strains used for challenge-tests.

2.4.2.2. Challenge-tests. Two-hundred gram meat portions aliquoted in sterile plastic bags were first frozen at $-20^{\circ} \mathrm{C}$ in order to minimize sensorial alteration, then sterilized by ionization at $12 \mathrm{kGy}$ (IONISOS, Sablésur-Sarthe, France) and maintained frozen until use. They were then thawed at $4{ }^{\circ} \mathrm{C}$ during $24 \mathrm{~h}$. Inoculation of the cocktail of $E$. coli strains to a final concentration of $10^{5} \mathrm{cfu} / \mathrm{g}$ was performed by kneading the bags for $2 \mathrm{~min}$ after the addition of $1 \mathrm{~mL}$ suspension in 200-g meat portions (inoculation rate of $0.5 \%$ ). Inoculated meat was then vacuumpacked and held at $4{ }^{\circ} \mathrm{C}$ overnight and randomly treated by high pressure by batches of 10 .

2.4.2.3. Modeling E. coli HHP-inactivation and regrowth. E. coli inactivation and subsequent growth kinetics were quantitatively analyzed from challenge-test data to build primary and secondary models of HHP-

Table 1

Inactivation of $E$. coli induced by $\mathrm{HHP}$ and its regrowth during storage at $8{ }^{\circ} \mathrm{C}$.

\begin{tabular}{|c|c|c|c|c|c|c|c|c|c|c|c|c|c|c|c|c|c|}
\hline \multicolumn{3}{|c|}{ HHP treatment } & \multicolumn{2}{|c|}{$\begin{array}{l}\text { E. coli post-HHP } \\
\text { data counts } \\
(\log \mathrm{cfu} / \mathrm{g})\end{array}$} & \multicolumn{9}{|c|}{ E. coli growth data counts ( $\log \mathrm{cfu} / \mathrm{g}$ ) } & \multicolumn{4}{|c|}{ Growth modeling } \\
\hline $\begin{array}{l}\text { Pressure } \\
\text { (MPa) }\end{array}$ & $\begin{array}{l}\text { duration } \\
\text { (min) }\end{array}$ & $\begin{array}{l}\text { \% lactate } \\
(w / v)\end{array}$ & $t=1 \mathrm{~d}$ & $\Delta \log _{\mathrm{HHP}}$ & $t=6 \mathrm{~d}$ & $t=7 \mathrm{~d}$ & $t=9 \mathrm{~d}$ & $t=12 \mathrm{~d}$ & $t=14 \mathrm{~d}$ & $t=16 \mathrm{~d}$ & $t=19 \mathrm{~d}$ & $t=22 \mathrm{~d}$ & $t=26 \mathrm{~d}$ & $\Delta \log _{\text {storage }}$ & $\mu_{\max \left(\mathrm{d}^{-1}\right)}$ & $\lambda(d)$ & $\mathrm{R}^{2}$ \\
\hline \multirow[t]{2}{*}{ NT } & 0 & 1.8 & 4.9 & 0 & 5.8 & 5.3 & 5.6 & 5.3 & 5.2 & 5.4 & 5.5 & 5.3 & 5.2 & 0.3 & & & \\
\hline & 0 & 1.8 & 5.2 & 0 & 5.9 & 5.9 & 5.8 & 5.6 & 5.9 & 5.8 & 5.4 & 5.4 & 5.5 & 0.4 & & & \\
\hline \multirow[t]{9}{*}{300} & 2 & 0.9 & 4.8 & -0.1 & 4.5 & 4.3 & 4.9 & 5.2 & 5.0 & 5.3 & 5.4 & 5.2 & 5.2 & 0.5 & 0 & 0 & \\
\hline & 2 & 0.9 & 3.9 & -1.3 & 4.3 & 4.5 & 4.5 & 4.9 & 5.0 & 5.4 & 5.7 & 5.7 & 5.4 & 1.6 & 0.264 & 0 & 0.940 \\
\hline & 6 & 0 & 3.9 & -1.0 & 3.9 & 3.9 & 4.3 & 4.6 & 4.9 & 5.4 & 6.3 & 6.0 & 6.6 & 2.8 & 0.360 & 6.60 & 0.959 \\
\hline & 6 & 0 & 2.0 & -3.2 & 3.2 & 2.4 & 2.6 & 3.2 & 3.1 & 3.5 & 4.7 & 4.7 & 6.3 & 4.3 & 0.384 & 4.04 & 0.882 \\
\hline & 10 & 2.7 & 4.5 & -0.4 & 4.7 & 4.7 & 4.8 & 4.9 & 5.5 & 5.9 & 6.1 & 6.5 & 6.9 & 2.5 & 0.326 & 7.72 & 0.978 \\
\hline & 10 & 2.7 & 4.0 & -1.2 & 4.1 & 4.3 & 4.2 & 4.2 & 4.3 & 4.3 & 4.4 & 4.5 & 4.3 & 0.3 & 0 & 0 & \\
\hline & 14 & 1.8 & 2.9 & -2.0 & 2.9 & 3.2 & 2.9 & 3.1 & 3.0 & 2.9 & 3.2 & 2.9 & 3.0 & 0.1 & 0 & 0 & \\
\hline & 14 & 1.8 & 2.9 & -2.2 & 3.1 & 3.0 & 3.1 & 3.1 & 3.3 & 3.0 & 3.2 & 3.3 & 4.3 & 1.4 & $N D$ & $N D$ & 0.537 \\
\hline & & & & & & & & & & & & & & \multicolumn{4}{|c|}{ Mean $\mu_{\max } \pm s d=0.17 \pm 0.181$} \\
\hline \multirow{8}{*}{400} & 2 & 2.7 & 4.7 & -0.1 & 4.6 & 4.7 & 3.5 & 4.4 & 4.2 & 4.5 & 4.5 & 4.6 & 4.5 & -0.3 & & & \\
\hline & 2 & 2.7 & 4.3 & -1.1 & 4.4 & 4.5 & 3.9 & 4.5 & 4.2 & 3.9 & 3.9 & 4.1 & 4.2 & -0.2 & & & \\
\hline & 6 & 1.8 & 3.4 & -1.5 & 2.6 & 3.8 & 3.4 & 3.1 & 3.0 & 3.2 & 3.1 & 3.0 & 3.2 & -0.2 & & & \\
\hline & 6 & 1.8 & 3.5 & -2.7 & 2.2 & 2.2 & 2.7 & 2.7 & 3.0 & 2.5 & 2.7 & 2.2 & 2.9 & -0.6 & & & \\
\hline & 10 & 0.9 & 1.7 & -3.2 & 1.7 & 1.7 & 2.0 & 1.7 & 1.7 & 1.7 & 1.7 & 1.7 & 2.2 & 0.5 & & & \\
\hline & 10 & 0.9 & 1.7 & -3.5 & 2.0 & 1.7 & 2.0 & 2.2 & 1.7 & 2.0 & 2.0 & 2.9 & 2.7 & 1.0 & $N D$ & $N D$ & 0.582 \\
\hline & 14 & 0 & 1.7 & -3.2 & 1.7 & 1.7 & 1.7 & 1.7 & 1.7 & 1.7 & 2.0 & 1.7 & 2.5 & 0.8 & $N D$ & $N D$ & 0.085 \\
\hline & 14 & 0 & 1.7 & -3.5 & 1.7 & 1.7 & 2.0 & 1.7 & 1.7 & 1.7 & 1.7 & 1.7 & 2.0 & 0.3 & & & \\
\hline \multirow[t]{8}{*}{450} & 2 & 1.8 & 3.2 & -1.7 & 3.0 & 2.5 & 3.5 & 2.9 & 2.9 & 3.0 & 3.0 & 3.1 & 2.4 & -0.8 & & & \\
\hline & 2 & 1.8 & 2.4 & -2.8 & 2.5 & 2.9 & 1.7 & 2.5 & 2.7 & 2.3 & 1.7 & 2.5 & 4.3 & 1.9 & $N D$ & $N D$ & 0.087 \\
\hline & 6 & 0.9 & 2.5 & -2.3 & 2.5 & 2.2 & 1.7 & 2.2 & 1.7 & 2.2 & 2.3 & 2.0 & 2.0 & -0.5 & & & \\
\hline & 6 & 0.9 & 2.3 & -2.9 & 1.7 & 1.7 & 2.0 & 2.3 & 2.5 & 2.7 & 2.2 & 2.0 & 2.4 & 0.1 & & & \\
\hline & 10 & 0 & 1.7 & -3.2 & 2.7 & 1.7 & 2.2 & 1.7 & 1.7 & 1.7 & 1.7 & 1.7 & 1.7 & 0.0 & & & \\
\hline & 10 & 0 & 1.7 & -3.5 & 1.7 & 1.7 & 1.7 & 1.7 & 1.7 & 2.2 & 1.7 & 1.7 & 1.7 & 0.0 & & & \\
\hline & 14 & 2.7 & 3.3 & -1.6 & 3.2 & 3.8 & 4.5 & 2.7 & 2.8 & 2.7 & 3.7 & 2.0 & 3.8 & 0.5 & & & \\
\hline & 14 & 2.7 & 3.0 & -2.1 & 3.3 & 2.9 & 3.1 & 3.1 & 3.2 & 2.7 & 3.2 & 2.7 & 2.7 & -0.3 & & & \\
\hline \multirow[t]{8}{*}{500} & 2 & 0 & 1.7 & -3.2 & 1.7 & 1.7 & 1.7 & 1.7 & 1.7 & 2.2 & 2.0 & 1.7 & 2.0 & 0.3 & & & \\
\hline & 2 & 0 & 2.2 & -3.0 & 1.7 & 1.7 & 2.2 & 2.2 & 1.7 & 1.7 & 1.7 & 1.7 & 1.7 & -0.5 & & & \\
\hline & 6 & 2.7 & 1.7 & -3.2 & 2.0 & 1.7 & 2.3 & 1.7 & 2.4 & 1.7 & 1.7 & 2.3 & 2.2 & 0.5 & & & \\
\hline & 6 & 2.7 & 1.7 & -3.5 & 2.2 & 2.0 & 2.7 & 1.7 & 1.7 & 1.7 & 1.7 & 1.7 & 2.7 & 1.0 & $N D$ & $N D$ & 0.008 \\
\hline & 10 & 1.8 & 2.5 & -2.3 & 2.5 & 2.2 & 1.7 & 2.0 & 2.2 & 2.4 & 2.2 & 2.2 & 2.0 & -0.5 & & & \\
\hline & 10 & 1.8 & 1.7 & -3.5 & 1.7 & 1.7 & 2.6 & 1.7 & 1.7 & 1.7 & 2.2 & 2.2 & 1.7 & 0.0 & & & \\
\hline & 14 & 0.9 & 1.7 & -3.2 & 1.7 & 1.7 & 1.7 & 1.7 & 1.7 & 1.7 & 1.7 & 2.2 & 1.7 & 0.0 & & & \\
\hline & 14 & 0.9 & 1.7 & -3.5 & 1.7 & 1.7 & 2.2 & 1.7 & 2.2 & 1.7 & 1.7 & 1.7 & 1.7 & 0.0 & & & \\
\hline
\end{tabular}

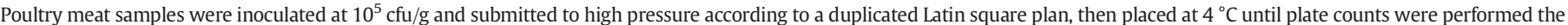

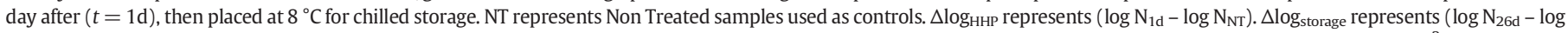

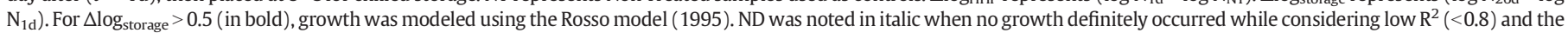
curve shape. 
induced inactivation and the growth model. In contrast with L. monocytogenes and Salmonella in the study of Lerasle et al. (2014), the Weibull model did not give satisfying results while modeling HHP-inactivation of $E$. coli (data not shown). Therefore the primary model used was adapted from the log linear model with tail (Eq. (1)) performed by Hereu et al. (2012) for the modeling of HHP-induced inactivation of $L$. monocytogenes in Ready To Eat (RTE) products

$\log (\mathrm{N})=\log \left[\left(10^{\log \left(\mathrm{N}_{0}\right)}-10^{\log (\mathrm{Nres})}\right) * \mathrm{e}^{-\mathrm{kmax} * \mathrm{t}}+10^{\log (\text { Nres })}\right]$

where $\mathrm{N}$, the microbial population after $\mathrm{t}$ duration ( $\mathrm{min}$ ), $\mathrm{N}_{0}$, the initial microbial population and $\mathrm{N}_{\text {res}}$, the residual microbial population, were expressed in $\mathrm{cfu} / \mathrm{g}$, and $\mathrm{k}_{\max }$, the inactivation rate in $\mathrm{min}^{-1}$.

The model of Hereu et al. (2012) was adapted to determine the microbial reduction as a function of the maximum expected microbial population reduction, $\Delta=\mathrm{N}_{\text {res }} / \mathrm{N}_{0}$ (Eq. (2)):

$\log (\mathrm{N})=\log \left(\mathrm{N}_{0}\right)+\log [(1-\Delta) * \exp (-\mathrm{kmax} * \mathrm{t})+\Delta]$

In Eq. (2), $\log \left(\mathrm{N}_{0}\right)$ was calculated as the mean value of raw data at $t=0$, it equaled 5.01. Therefore, there were only two estimated parameters: kmax and $\Delta$. A first secondary model was set to assess whether the two parameters were dependent on high pressure intensity (HPi). Only the inactivation rate, kmax, was found to be significantly influenced by HPi $(P<0.05)$ (data not shown). Therefore, the secondary model was simplified as follows (Eq. (3)):

$\log \left(\mathrm{k}_{\max }\right)=\mathrm{b}+(\mathrm{HPi}-\mathrm{MeanHPi}) * \mathrm{a}$

In Eq. (3), MeanHPi is the mean of HPi; MeanHPi $=415 \mathrm{MPa}$. When HPi equals MeanHPi, b equals $\log \left(\mathrm{k}_{\max }\right): \mathrm{b}=\mathrm{b}$ is expressed in $\log$ $\min ^{-1}$; $a$ is expressed in $\mathrm{MPa}^{-1}$.

Primary (Eq. (2)) and secondary modeling (Eq.(3)) were simultaneously run to predict $\log (\mathrm{N})$ as a function of HPi and treatment duration (HPd), as recommended by Van Derlinden et al. (2008) to have accurate parameter estimates. To sum up, the variables to conservative adjust were: $\Delta$, a and $\mathrm{b}$.

Model performance procedure was performed using $\mathrm{R}$ software (Team, 2010). The "nls" function was used for conducting nonlinear regression, and the numerical process for parameter estimation was based on the Gauss-Newton algorithm. R package, "nlstools," was used to test the significance of the model parameters and the correlation matrix provided as supplementary materials.

For all post-HPP growth kinetics, a quantitative criteria $\Delta$ log was calculated from the difference between the concentration of $E$. coli cells at the end of the 26-d chilled storage period and its concentration just after HHP treatment $\left(\Delta \log _{\text {storage }}=\log \mathrm{N}_{26 \mathrm{~d}}-\log \mathrm{N}_{1 \mathrm{~d}}\right)$ (Table 1$)$. It was considered that when $\Delta \log$ was below 0.5 , no growth occurred at $8{ }^{\circ} \mathrm{C}$. For kinetics with $\Delta \log \geq 0.5$, growth was modeled using the Rosso model (Rosso, 1995) with the determination of lag phase duration $(\lambda)$, maximum specific growth rate $\left(\mu_{\max }\right)$, logarithm of maximum population density $\left(\log \left(\mathrm{X}_{\infty}\right)\right)$ and initial population density $\log \left(\mathrm{X}_{0}\right)$ (Eq. (4)).

$\begin{array}{ll}X=X_{0} & \text { if } t<\lambda \\ X=X_{\infty} /\left[1+\left(\left(X_{\infty} / X_{0}\right)-1\right) \cdot \exp \left(-\mu_{\max }(t-\lambda)\right)\right] & \text { if } t>\lambda\end{array}$

Parameter estimation was also run in $\mathrm{R}$ with the nls function.

We considered that $\mathrm{R}^{2} \geq 0.8$ attested for an acceptable fit of the model, otherwise, $\mu_{\max }$ was set to zero. At HPi equals or higher than $400 \mathrm{MPa}$, no growth was observed. At $300 \mathrm{MPa}$, linear regressions were performed to study the influence of lactate and pressure intensity on maximum specific growth rate and lag phase durations. With the number of observations available, neither the maximal growth rate nor the lag phase duration were found to be influenced by lactate concentration and treatment duration (data not shown). In the subsequent probabilistic model, at $300 \mathrm{MPa}, \mu_{\max }$ was implemented as a Normal distribution with mean $\mu_{\max }$ calculated from growth curves subsequent to 300-MPa treatments: $\mu_{\max } \sim \mathrm{N}\left(\right.$ mean $\mu_{\max }$; sd $\left.\mu_{\max }\right)$. At pressures above $300 \mathrm{MPa}, \mu_{\max }=0$.

Hereunder, the models, i.e. initial contamination model (Section 2.4.1), HHP-inactivation model (Section 2.4.2.3), regrowth model (Section 2.4.2.3) were incorporated into the probabilistic model of exposure (Table 2).

\subsection{Probabilistic model implementation}

Resulting from the four steps described above, a probabilistic model of E. coli was built to estimate the distribution of the contamination level of E. coli at the end of the shelf-life (Table 2). Similar exposure assessment models of L. monocytogenes and Salmonella previously developed were used to estimate the distribution of the contamination level of L. monocytogenes and Salmonella (Lerasle et al., 2014). For the three microorganisms, the different scenarios were run with varying HPi from 300 to $500 \mathrm{MPa}$, and HPd from 0 to $15 \mathrm{~min}$, lactate concentration (current concentration, i.e. $1.8 \%(w / w)$ or at $0 \%$ ) and storage time (current shelf-life of 15 days to 26 days). The chilled storage temperature was defined according to the French norm NF V01-003 on shelf-life studies of chilled perishable and highly perishable food (AFNOR, 2010). Accordingly, the temperature was set at $4{ }^{\circ} \mathrm{C}$ for the first two-third of the shelf-life duration, then to $8{ }^{\circ} \mathrm{C}$ for the last third of the period $\left(4{ }^{\circ} \mathrm{C}(2 / 3 \mathrm{SL})\right.$ and $8{ }^{\circ} \mathrm{C}$ $(1 / 3 \mathrm{SL}))$. As a worst case, during storage, for $E$. coli, maximal growth rate was assumed to be the same for a chilled storage performed entirely at $8{ }^{\circ} \mathrm{C}$ as for the two-step storage $\left(2 / 3\right.$ at $4{ }^{\circ} \mathrm{C}$ and $1 / 3$ at $\left.8{ }^{\circ} \mathrm{C}\right)$ and, as a conservative choice, lag was set at 0 .

All models implemented in the Excel add-in @Risk (version 6.0, Palisade, Newfield, NY) were run using the Monte Carlo simulation technique. For each step of the models, the outputs were the probability distribution of the contamination level. According to the probability theory, the cumulative distribution function $F(x)$ gives the probability that the variable $X$ is less than or equal to $x$ (Vose, 2008): $F(x)=$ $P(X \leq x)$. It can also be defined as the probability for which the microbiological criteria $x$ is fulfilled. The prevalence rate was deduced from $F(0)$ : Prevalence $=1-F(0)=1-\operatorname{Pr}(X \leq 0)$ with $X$ the quantity in the $200 \mathrm{~g}$ portion.

For each simulation associated with one scenario, 1 million iterations were generated. One iteration corresponded to one 200-g minced meat portion going through a given scenario.

\subsection{Sensory analysis}

\subsubsection{Triangle test}

Two-hundred gram raw poultry meat samples were pressurized into 4 batches of 18 samples at 300 and 500 MPa for 5 min or untreated ( 72 samples each). Previously to sensory analysis, samples were paned for 10 min on each face and kept warm in an oven at $100{ }^{\circ} \mathrm{C}$ before consumption. A triangle test was performed to examine if panelists were able to differentiate high pressure-treated samples from controls. Three tests were randomly proposed to each judge of an untrained panel of 24 people in order to compare two by two, 300-MPa versus control samples, 300-MPa versus 500-MPa samples and 500-MPa versus control samples. After smelling and tasting in the order specified, the panelists were then asked to identify which sample among the three coded ones was different from the two others. For interpretation of the triangle test, the binomial distribution was used to test the null hypothesis that the number of correct responses was smaller or equal to the probability of giving the correct answer $(p c)$ by chance of $1 / 3$.

The probability that the $\mathrm{x}$ correct responses corresponded to a sensory difference between the samples is calculated as below:

$\mathrm{P}(\mathrm{X}>\mathrm{X})=\sum_{i=x}^{n} C_{i}^{n} \cdot p c^{i} \cdot(1-p c)^{n-i}-C_{x}^{n} \cdot p c^{x} \cdot(1-p c)^{n-x}$ 
Table 2

Detailed overview of the probabilistic model for exposure to E. coli.

\begin{tabular}{|c|c|c|c|c|c|}
\hline Module & Variable & Description & Unit & Distribution/models (@risk notation) and assumptions/references & Data \\
\hline \multirow[t]{3}{*}{$\begin{array}{l}\text { (1) Initial } \\
\text { contamination } \\
\text { level of } 100-\mathrm{kg} \\
\text { meat batches }\end{array}$} & $\mathrm{n}_{25}$ & $\begin{array}{l}\text { Concentration of bacteria in } \\
25 \text {-g samples contaminated by } \\
\text { E. coli for each sampling } \\
\text { campaign }\end{array}$ & $\begin{array}{l}\log \\
\mathrm{cfu} / \mathrm{g}\end{array}$ & & $\begin{array}{l}\text { Based on dataset of } \\
563 \log \text { counts of } E \text {. } \\
\text { coli collected in this } \\
\text { study }\end{array}$ \\
\hline & $\mathrm{M}_{25}, \mathrm{~S}_{25}$ & $\begin{array}{l}\text { The average concentration of } \\
\text { bacteria and standard error in } \\
25 \text {-g samples contaminated by } \\
\text { E. coli }\end{array}$ & $\begin{array}{l}\log \\
\mathrm{cfu} / \mathrm{g}\end{array}$ & $\begin{array}{l}\mathrm{M}_{25}=1.69 \\
\mathrm{~S}_{25}=0.72 \\
\mathrm{~F}_{25}=\operatorname{RiskNormal}\left(\mathrm{M}_{25}, \mathrm{~S}_{25}\right)\end{array}$ & \\
\hline & $\mathrm{F}_{25}$ & Frequency distribution of $E$. coli & & & \\
\hline \multirow[t]{2}{*}{$\begin{array}{l}\text { (2) Partitioning } \\
\text { and packaging }\end{array}$} & $\mathrm{N}_{200}$ & $\begin{array}{l}\text { Concentration of bacteria in a } \\
200-\mathrm{g} \text { packs }\end{array}$ & $\begin{array}{l}\mathrm{cfu} / 200 \\
\mathrm{~g}\end{array}$ & $\mathrm{~N}_{200}=$ RiskPoisson $\left(10^{\wedge} \mathrm{F}_{25} \cdot 200\right)$ & \\
\hline & Prev $_{\text {packs }}$ & $\begin{array}{l}\text { Prevalence: number of } \\
\text { contaminated packs }\end{array}$ & $\%$ & $\operatorname{Prev}_{\text {packs }}=\left(1-\operatorname{RiskTarget}\left(\mathrm{N}_{200} ; 0\right)\right) \cdot 100$ & \\
\hline \multirow[t]{5}{*}{$\begin{array}{l}\text { (3) High Pressure } \\
\text { treatment }\end{array}$} & $\log R$ & $\begin{array}{l}\text { Bacterial log decimal reduction } \\
\text { Nres, residual bacterial } \\
\text { concentration cfu/g; } \mathrm{k}_{\max } \\
\text { inactivation rate } \\
\mathrm{t}, \text { HHP duration ( } \mathrm{min})\end{array}$ & & $\begin{array}{l}\text { Log linear model with tail (Hereu et al. 2012): } \\
\log R=\log \left[\left(10^{\log \left(\mathrm{N}_{0}\right)}-10^{\log (\mathrm{Nres})}\right) \cdot \exp \left(-\mathrm{k}_{\max } \mathrm{t}\right)+10^{\log (\mathrm{Nres})}\right]-\log \left(\mathrm{N}_{0}\right)\end{array}$ & $\begin{array}{l}\text { HHP-inactivation } \\
\text { data from Latin } \\
\text { square design } \\
\text { performed in this } \\
\text { study }\end{array}$ \\
\hline & & & & $\begin{array}{l}\log \left(\mathrm{k}_{\max }\right)=\mathrm{b}+\mathrm{a} .(\mathrm{HPi}-\mathrm{MeanHPi}) \text { (No effect of lactate concentration on } \\
\text { inactivation) }\end{array}$ & \\
\hline & PrHP & $\begin{array}{l}\text { Probability of bacteria to } \\
\text { survive HHP }\end{array}$ & & $\operatorname{PrHP}=10^{-\log R}$ & \\
\hline & $\mathrm{N}_{\text {post-HP }}$ & $\begin{array}{l}\text { Concentration of bacteria } \\
\text { surviving to HHP }\end{array}$ & $\begin{array}{l}\mathrm{cfu} / 200 \\
\mathrm{~g}\end{array}$ & $\mathrm{~N}_{\text {post-HP }}=$ RiskPoisson $\left(\mathrm{N}_{200} \cdot\right.$ PrHP $)$ & \\
\hline & PrevHP & $\begin{array}{l}\text { Number of contaminated packs } \\
\text { after HHP }\end{array}$ & $\%$ & PrevHP $=\left(1-\right.$ RiskTarget $\left.\left(\mathrm{N}_{\text {post-HP }} ; 0\right)\right) \cdot 100$ & \\
\hline \multirow[t]{6}{*}{ (4) Storage } & $\mu_{\max }$ & $\begin{array}{l}\text { Distribution of maximal growth } \\
\text { rate of } E \text {. coli during storage at } \\
8^{\circ} \mathrm{C} \text { in case of growth } \\
\text { occurrence }\end{array}$ & $d^{-1}$ & $\begin{array}{l}\mu_{\max }=\text { RiskNormal (Mean } \mu_{\max } ; s d \mu_{\max } \text { ) (No significant effect of HPi and } \\
\text { lactate) }\end{array}$ & $\begin{array}{l}\text { Regrowth data } \\
\text { from Latin square } \\
\text { design performed } \\
\text { in this study }\end{array}$ \\
\hline & $\begin{array}{l}\mathrm{M} \mu_{\max } \\
\mathrm{sd} \mu_{\max }\end{array}$ & $\begin{array}{l}\text { The average } \mu_{\max } \text { among } \\
\text { growth curves following } \\
\text { 300-MPa HHP treatments and } \\
\text { standard error }\end{array}$ & $d^{-1}$ & & \\
\hline & $\mathrm{t}_{\text {storage }}$ & Time of storage & $\mathrm{d}$ & & \\
\hline & $\log N_{S L}$ & $\begin{array}{l}\text { Concentration of } E \text {. coli cells at } \\
\text { the end of the set shelf-life }\end{array}$ & $\begin{array}{l}\log \\
\mathrm{cfu} / 200 \\
\mathrm{~g}\end{array}$ & $\left\{\begin{array}{cc}\log N_{S L}=\log N_{\text {post }-\mathrm{HP}}+\mu_{, \text {max }} \cdot t_{\text {storage }} & \text { if } \mathrm{HPi} \leq 300 \mathrm{MPa} \text { (No growth after } \\
\log N_{\mathrm{SL}}=\log N_{\text {post }-\mathrm{HP}} & \text { if } \mathrm{HPi}>300 \mathrm{MPa} \text { application of HHP } \\
& \text { above } 300 \mathrm{MPa})\end{array}\right.$ & \\
\hline & PrevSL & $\begin{array}{l}\text { Number of contaminated packs } \\
\text { after storage }\end{array}$ & $\%$ & PrevSL $=\left(1-\right.$ RiskTarget $\left.\left(\mathrm{N}_{\mathrm{SL}} ; 0\right)\right) \cdot 100$ & \\
\hline & $\begin{array}{l}\mathrm{P}(\mathrm{X} \leq \\
\left.\mathrm{N}_{\text {upperlimit }}\right)\end{array}$ & $\begin{array}{l}\text { Probability that the } \\
\text { concentration of } E \text {. coli is below } \\
\text { the criterion } \mathrm{N}_{\text {upperlimit in } 200-\mathrm{g}} \\
\text { packs }\end{array}$ & $\%$ & $\mathrm{P}\left(\mathrm{X} \leq \mathrm{N}_{\text {upperlimit }}\right)=\left(\right.$ RiskTarget $\left(\right.$ PrevSL; $\left.\left.\mathrm{N}_{\text {upperlimit }} \cdot 200\right)\right) \cdot 100$ & \\
\hline
\end{tabular}

For $n=24$ assessors, the number of the correct responses, $\mathrm{x}$, has to be above 13 so that the risk $\alpha=1-P(X>x)$ that these responses were given by chance is $<0.05$ (ISO, 2004).

\subsubsection{Descriptive sensory analysis}

The descriptive sensory analysis was conducted by a semi-trained panel of minimum 10 assessors (Heymann et al., 2012) with previous experience in sensory evaluation of various meat products and particularly of these products. The generation of the descriptors for the meat was carried out by the assessors with a non-structured scoring scale (0: absence; 10: high intensity). Two-hundred gram meat coded samples pressurized or not were randomly presented to the assessors to be given a rate for every descriptor. Ratings were then averaged and eventually assigned a negative sign for descriptors having a negative impact on the product quality. Each assessor was asked to rate one treated and one untreated samples.

For the determination of the organoleptic window, samples were simultaneously pressurized at $300 \mathrm{MPa}$ during 5 min or $500 \mathrm{MPa}$ during 5 min or unpressurized (control). Sensory analysis was performed the day after HHP by 10 assessors.

For the validation experiment, the panel was constituted of 23 judges for better evaluation. Samples were pressurized at the set HHP conditions to be validated, or not pressurized for controls then stored at $4{ }^{\circ} \mathrm{C}$ respectively for two-third of the extended or current shelf-life and for the remaining time at $8{ }^{\circ} \mathrm{C}$. Sensory analysis was performed 2 days before the targeted extended shelf-life with $L$. monocytogenes counts available for pressurized samples. For controls, it was performed at the current shelf-life of 15 days. Additionally, an acceptance test was performed after cooking on products whose shelf-life had to be validated.

\subsubsection{Color analysis}

Instrumental color (CIE L*, $a^{*}, b^{*}$; CIE, 1976) was measured on the surface of poultry meat using a Minolta spectrophotometer CM-3500d (Konica Minolta, Japan). Measurements were made the day of HHP on five points inside an 8-mm diameter measurement area defined by a target mask. Three color indices were obtained: $\mathrm{L}^{*}$ (lightness), $\mathrm{a}^{*}$ (redness) and $\mathrm{b}^{*}$ (yellowness) values. Measurements were performed in duplicate on unpressurized (controls) and HHP-treated 200-g meat portions for $5 \mathrm{~min}$ at 200, 300 and $400 \mathrm{MPa}$.

Statistical analysis of color measurements and descriptive analysis was performed by analysis of Variance, Fisher's Least Significant Difference (LSD) carried out with the XLSTAT 2014 statistical package (Addinsoft, France). 


\subsection{Validation experiments}

Once a new shelf-life (longer than the current one set of 15 days) was suggested by combining the three criteria, a validation was performed. For validation, naturally contaminated meat samples were used to get rid of the hypothetical bias related to the ionization and the inoculation procedures. For practical purposes, samples were first frozen at $-20^{\circ} \mathrm{C}$, then allowed to thaw at $4{ }^{\circ} \mathrm{C} 48 \mathrm{~h}$ before pressurization. The core temperature of the products was checked before pressurization and found to be $3{ }^{\circ} \mathrm{C} \pm 0.2^{\circ} \mathrm{C}$. All samples were pressurized the same day. The current (unpressurized) product at the end of the current shelf-life (15 days) considered as the control was used as a basis for comparison with the pressurized product with extended shelf-life. Accordingly, safety, hygienic and organoleptic criteria were determined on the control at the current shelf-life and on the pressurized product at the extended shelf-life. According to the microbiological criteria established by French Trade and Retail Federation, the concentration of LAB should be below $10^{7} \mathrm{cfu} / \mathrm{g}$ at the end of the shelf-life (FCD, 2010). Therefore, in addition to the selected hygienic (E. coli) and safety indicators (Salmonella and L. monocytogenes), LAB were also enumerated. The validation was performed on six different batches of the current product containing $1.8 \%$ lactate produced at two seasonal periods. After pressurization or not, samples were stored as follows: two-third of the extended shelf-life at $4{ }^{\circ} \mathrm{C}$ and the remaining third at $8^{\circ} \mathrm{C}$. Five replicates were used by batch and by storage point.

\section{Results}

\subsection{Probabilistic assessment model of E. coli}

\subsubsection{Estimation of initial contamination by E. coli: $N_{200}$}

The first step enabled to determine the initial contamination of $E$. coli in 200-g samples, $\mathrm{N}_{200}$. The mean contamination level was estimated to $1.69 \log \mathrm{cfu} / \mathrm{g}$ (Table 3). Before storage, the probability that the concentration of $E$. coli in $200-\mathrm{g}$ portions is $<5.10^{3} \mathrm{cfu} / \mathrm{g}$, was found to be $99.74 \%$. As a consequence, under the current conditions (1.8\% lactate in the product formulation, shelf-life of 15 days), it appeared that the hygienic criterion was not fulfilled at a frequency of $0.26 \%$ even at the beginning of the storage. Therefore, the application of high pressure was required to achieve better hygienic quality of the final product, whether it contained lactate or not.

\subsubsection{Estimation of E. coli contamination following HHP: $N_{\text {post-HP }}$}

Inactivation of E. coli induced by HHP treatment is shown in Table 1. Data were analyzed by applying simultaneously primary and secondary models. The model error was found to be $0.5 \log \mathrm{cfu} / \mathrm{mL}$, which is compatible with commonly accepted for microbiological experimental error (Pujol et al., 2012). The parameters of the model were shown to be significant $(P<0.05)$ (Table S1 in supplementary materials). The mean parameter values and $95 \%$ confidence intervals $(\mathrm{CI})$ of the model were as follows:

$\Delta=1.06 \times 10^{-3}\left(\mathrm{CI} 4.6 \times 10^{-4}-1.7 \times 10^{-3}\right)$, adimensional,

$\mathrm{a}=5.9 \times 10^{-3} \mathrm{MPa}^{-1}\left(\mathrm{CI} 4.5 \times 10^{-3}-7.3 \cdot 10^{-3} \mathrm{MPa}^{-1}\right)$ and

$\mathrm{b}=0.13 \log \mathrm{min}^{-1}\left(\mathrm{Cl} 0.019-0.23 \log \mathrm{min}^{-1}\right)$.

Furthermore, the parameters of the model were shown not to be correlated $(r \leq 0.5)$ (Table S2). The comparison of observed versus fitted contamination levels of $E$. coli after application of HHP (Fig. S1) and expression of model residuals as a function of HPi and HPd did not identify any significant bias in the model (Fig. S2).

To make some comparisons with linear models, $\mathrm{k}_{\max }$ can be related to the reverse of the decimal reduction time $\mathrm{D}\left(\mathrm{D}=2.303 / \mathrm{k}_{\max }\right)$. Consequently, the reverse of the slope, a, in Eq. (2), can similarly be related to $\mathrm{Z}_{\mathrm{HP}}$, the pressure increase which provides one-log reduction of $\mathrm{D}$. In this

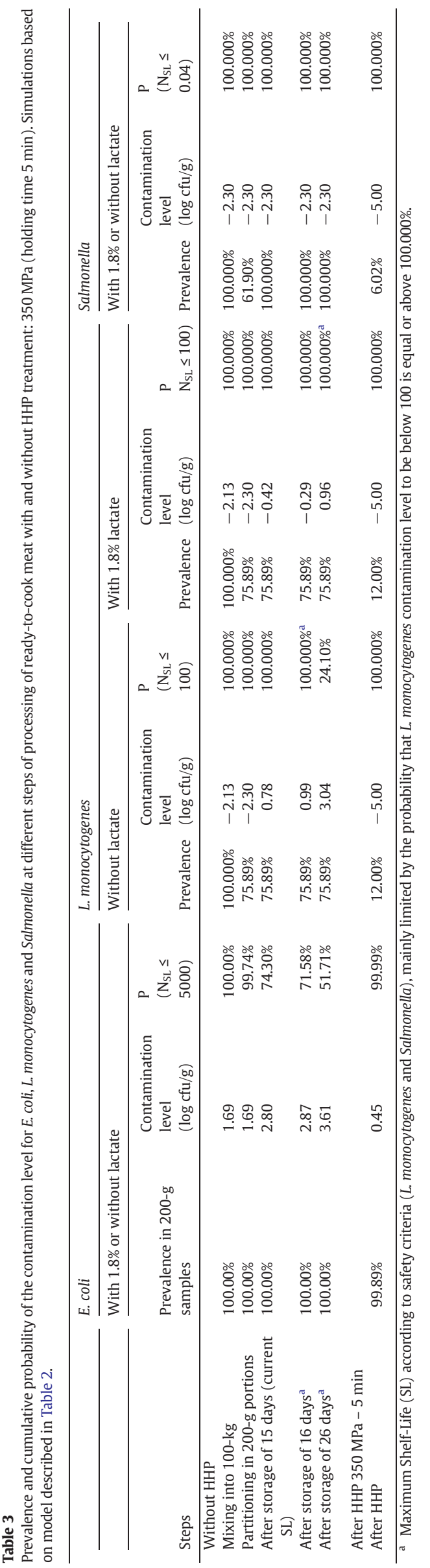


context, $\mathrm{Z}_{\mathrm{HP}}$ was found to be $170 \mathrm{MPa}$ and $\mathrm{D}$ was found to be $8,2,1$ and 0.5 min respectively at 300, 400, 450 and $500 \mathrm{MPa}$.

Using the HHP-induced inactivation model, it was then possible to predict the contamination level of E. coli after application of HHP,

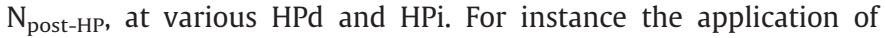
$350 \mathrm{MPa}$ for $5 \mathrm{~min}$ was sufficient to bring to $99.99 \%$ the probability that the concentration of $E$. coli in $200-\mathrm{g}$ units to be $<5.10^{3} \mathrm{cfu} / \mathrm{g}$. The prevalence of $E$. coli following this treatment was found to be $99.89 \%$ and its concentration, $0.45 \log \mathrm{cfu} / \mathrm{g}$ (Table 3 ).

\subsubsection{Estimation of E. coli contamination at the end of the shelf-life: $N_{S L}$}

The last step of the model was to assess the behavior of $E$. coli, during the storage in chilled conditions until the end of the shelf-life. Results from growth experiments are described in Table 1. For unpressurized samples, no growth of E. coli occurred during storage at $8{ }^{\circ} \mathrm{C}$, i.e. $\Delta \log _{\text {storage }}<0.5$ (Table 1 ). For most pressurized samples, no growth occurred either during chilled storage. Results of lag phase duration $(\lambda)$, maximum specific growth rate $\left(\mu_{\max }\right)$ estimated for samples in which $\Delta \log _{\text {storage }}>0.5$, are reported in Table 1 . At last, growth was shown only to occur in some samples ( 4 out of 8 ) treated at $300 \mathrm{MPa}$. Moreover no statistical analysis could attest for a lactate effect on $E$. coli growth (data not shown).

Consequently, it was considered that after a 300-MPa high pressure treatment, regardless of the treatment duration and whether lactate was added or not, growth of $E$. coli occurred at $8{ }^{\circ} \mathrm{C}$ with a mean maximal growth rate mean $\mu_{\max } 0.17 \mathrm{~d}^{-1}$ and standard error of 0.181 (Table 1). In the model of E. coli growth after a 300-MPa treatment, as a worst case, the lag was set to zero (conservative assumption) and $\mu_{\max }$ calculated from kinetics performed at $8{ }^{\circ} \mathrm{C}$ were used for the chilled storage. As E. coli did not grow in unpressurized samples and was observed only to grow in half of the samples pressurized at $300 \mathrm{MPa}$ and in none of the samples pressurized at HPi equal or above $400 \mathrm{MPa}$, it was assumed that no growth would neither occur between 300 and $400 \mathrm{MPa}$.

\subsection{Operational window for hygienic criteria}

The level of $E$. coli at the end of the shelf-life was estimated using the probabilistic model developed in the previous section. The probabilistic model made the hypothesis of E. coli growth after a 300-MPa treatment. Under this assumption, even a HPd of 20 min of 300-MPa application would not be strong enough to compensate the log increase and meet the hygienic criterion. Hence, HHP conditions favoring growth of $E$. coli during chilled storage had to be excluded from the operational window (dashed areas in Fig. 2). The role of high pressure will be then to decrease the initial contamination of E. coli to move from $99.74 \%$ to $100.00 \%$ the probability of having $<5.10^{3} \mathrm{cfu} / \mathrm{g}$. A mild high pressure treatment of $360 \mathrm{MPa}$ during $5 \mathrm{~min}$ (Fig. 2) could enable for example to achieve these requirements.

\subsection{Operational windows for safety criteria}

\subsubsection{Operational window for Salmonella}

The probabilistic model previously developed by Lerasle et al. (2014) did not include any growth module for Salmonella as it was considered not to grow under chilled temperature and $\mathrm{CO}_{2}$ atmosphere packaging. By running the model, it was shown that the Salmonella criterion was already met before storage without application of HHP $\left(\mathrm{P}\left(\mathrm{N}_{200}<0.04\right)>99.999 \%\right)$. Therefore Salmonella criterion constituted no obstacle to shelf-life extension, whatever formulation applied and even without HHP (Table 3).

\subsubsection{Operational window for L. monocytogenes}

In contrast with Salmonella, growth of L. monocytogenes was shown to occur during refrigerated storage under modified atmosphere (Lerasle et al., 2014). Therefore, it highly conditions the maximum

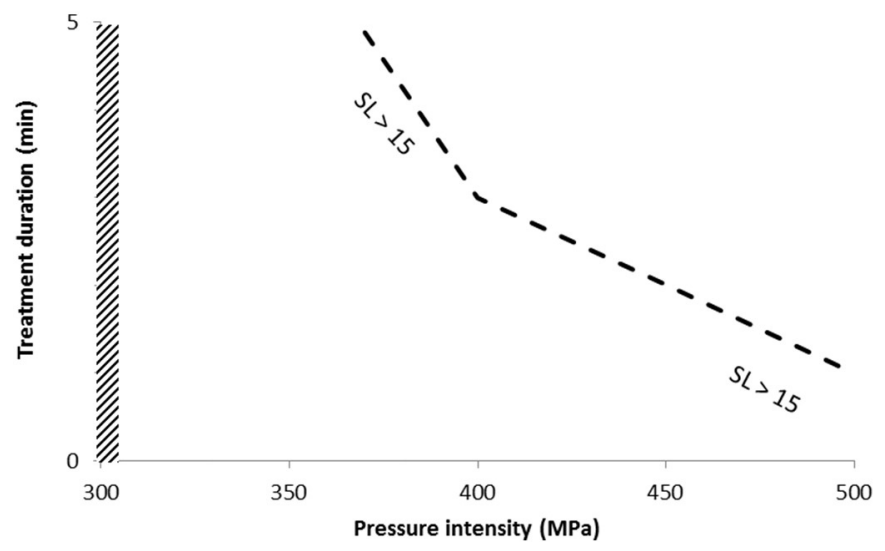

Fig. 2. Operational windows regarding E. coli criteria for a shelf-life (SL) equal or above 15 days during a chilled storage sequentially at $4{ }^{\circ} \mathrm{C}$ for $2 / 3$ SL and $8{ }^{\circ} \mathrm{C}$ for $1 / 3$ SL with $1.8 \%(w / w)$ lactate or without lactate addition. The operational window defines the set of combinations of HP intensity and duration enabling to fulfill the hygienic criteria, i.e. the probability that the concentration of $E$. coli in $200 \mathrm{~g}$ portions below $5.10^{3} \mathrm{CFU} / \mathrm{g}$ exceeds $99.99 \%$. It is defined by the area above the dashed line.

chilled storage duration enabling to meet the L. monocytogenes criterion, i.e. the probability that its concentration in $200-\mathrm{g}$ portions below $10^{2} \mathrm{cfu} / \mathrm{g}$ exceeds $99.999 \%$. By running the probabilistic model associated with L. monocytogenes, it was shown that without application of HHP, the $L$. monocytogenes criterion could be met for a storage duration below 26 days or 16 days whether lactate is present or not in the formulation (Table 3 ). Without lactate addition, to extend the shelf-life to > 16 days, application of HHP would be necessary.

By considering, this time, scenarios in which HHP was applied, the model estimated that, in absence of lactate, it was possible to extend the shelf-life to maximum 20 days with for example a HHP treatment of $10 \mathrm{~min}$ at $450 \mathrm{MPa}$ (Fig. 3a). On the contrary no HHP treatment was required to extend the shelf-life until 26 days since $1.8 \%$ lactate was added in the product formulation (Fig. $3 \mathrm{~b}$ ).

\subsection{Operational window for organoleptic criteria}

\subsubsection{Discrimination test: triangle test}

From the triangle test, it was shown that the untrained panel was unable neither to discriminate samples treated at $300 \mathrm{MPa}$ from the untreated ones (9 out of 24 correct answers) nor samples treated at $300 \mathrm{MPa}$ from that treated at $500 \mathrm{MPa}$ (12 out of 24 correct answers). On the other hand, $54 \%$ of the responses considered that the 500-MPa treated samples were different from the controls. From this first approach, the HHP treatment performed of $500 \mathrm{MPa}$ was shown to induce significant perceptible alterations that even untrained people were able to detect $(P<0.05)$. Considering this test, however, it was not possible to determine if the alterations perceived by the panel were acceptable or not. To appreciate more specifically the alterations induced by HHP, a descriptive sensory analysis was then performed on products treated at HPi of 300 and $500 \mathrm{MPa}$.

\subsubsection{Descriptive sensory analysis}

Fig. 4 describes mean ratings obtained from the panel of 10 assessors. The analysis of variance enabled to show that four descriptors were significantly affected by HHP $(P<0.05)$. These are tenderness, elasticity, juiciness and raw appearance, the latter being the most negatively impacted by high pressure $(P<0.0001)$, especially at $500 \mathrm{MPa}$. On the contrary, HHP was shown to induce rather beneficial effects on the product quality with increased tenderness and juiciness, and decreased elasticity. Consequently the only negative impact of HHP seemed to be associated to raw appearance and especially at $500 \mathrm{MPa}$. 
a

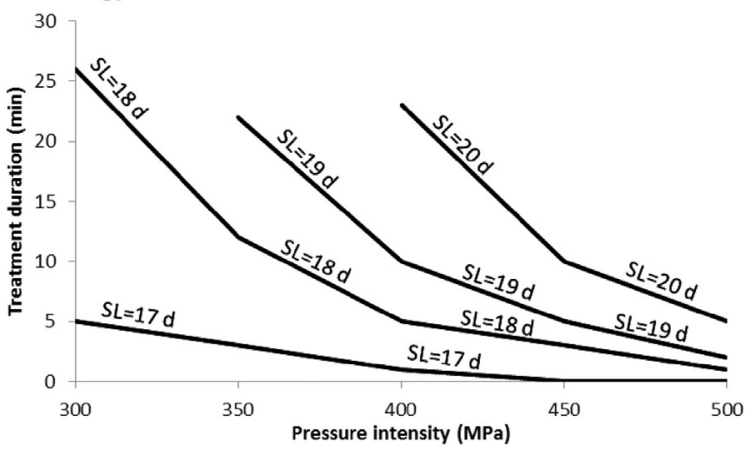

b

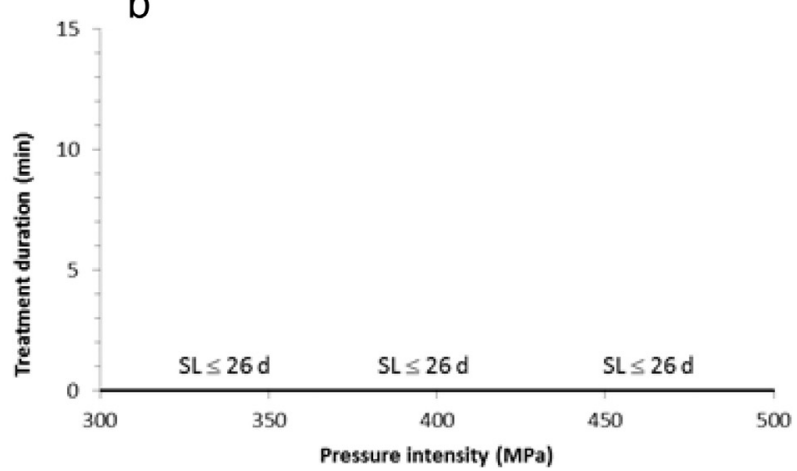

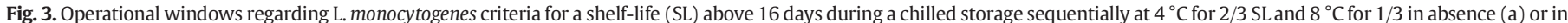

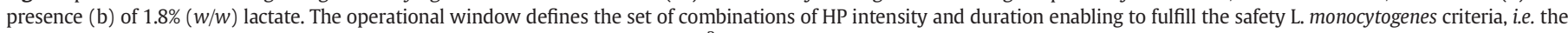

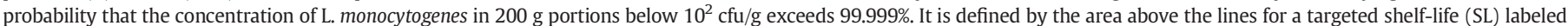

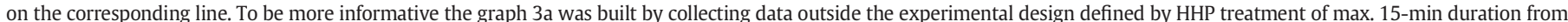
300 to $500 \mathrm{MPa}$.

\subsubsection{Color measurements}

Color is an important component of raw appearance and color alteration was visibly perceptible for products treated at $500 \mathrm{MPa}$. To determine more accurately the maximal pressure intensity which could be applied to the product with limiting effects on color and raw appearance, color measurements were performed on products treated during $5 \mathrm{~min}$ at $200 \mathrm{MPa}, 300 \mathrm{MPa}, 400 \mathrm{MPa}$ and not treated products (Table 4 ). The analysis of variance has shown that the two color components $\mathrm{a}^{*}$ and $\mathrm{b}^{*}$ were not significantly influenced by HPi $(P>0.05)$. On the other hand, HPi was found to increase significantly the $L^{*}$ parameter associated to lightening $(P<0.05)$. The LSD test has shown that samples treated above $400 \mathrm{MPa}$ had significant lower $L^{*}$ values than the other ones $(P<0.05)$. Consequently, because of their lightening detrimental effect on raw appearance, treatments performed for $5 \mathrm{~min}$ at HPi above 400 MPa were excluded from the organoleptic window (Fig. 5).

\subsection{Selection of the high pressure treatment enabling to achieve a targeted shelf-life}

The safety criteria and particularly associated with L. monocytogenes, made it impossible to remove lactate from the current formulation if the targeted shelf-life exceeded 20 days even with high pressure application. A HHP treatment of $350 \mathrm{MPa}$ during 5 min could only extend the shelf-life to 17 days, giving thus a 2-day gain. Therefore, it was considered that lactate could not be removed if one week extension of the shelf-life was targeted. After superimposition of organoleptic, safety and hygienic windows, it appeared that the hygienic and organoleptic criteria were decisive in the determination of the appropriate HHP treatment enabling to fulfill all criteria and achieve a shelf-life of $>15$ days (Fig. 5). Indeed application of HHP is required to improve the hygienic quality whatever shelf-life targeted, whereas HHP treatments could not exceed $400 \mathrm{MPa}$ ( $5 \mathrm{~min}$ ), not to alter raw appearance. The resulting operational window meeting all criteria $(\mathrm{S}, \mathrm{H}, \mathrm{O})$ could be defined by the triangle area included treatments performed at $360 \mathrm{MPa}$ during $5 \mathrm{~min}$ and at $400 \mathrm{MPa}$ from 3 to $5 \mathrm{~min}$ ( $300 \mathrm{MPa}$ excluded). To validate the approach, a treatment of $370 \mathrm{MPa}$ during $5 \mathrm{~min}$ in the area $(\mathrm{S}, \mathrm{H}, \mathrm{O})$, was experimentally tested for a one week gain of the current shelf-life of 15 days, thus bringing it to 22 days.

\subsection{Validation of the multi-criteria framework}

To validate the framework, the safety, hygienic and organoleptic criteria were evaluated following application in 6 batches of $370 \mathrm{MPa}$ for $5 \mathrm{~min}$, then stored during 22 days according to the French protocol used for shelf-life determination (AFNOR, 2010). E. coli was found below the detection limit of $1 \log \mathrm{cfu} / \mathrm{g}$ in pressurized samples whereas

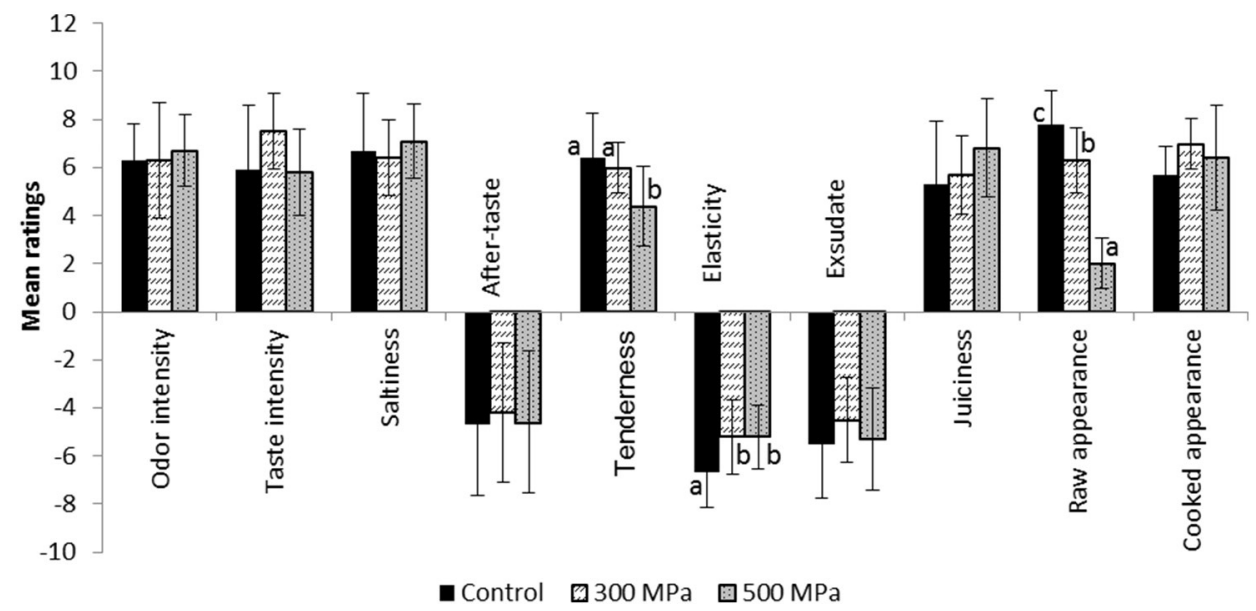

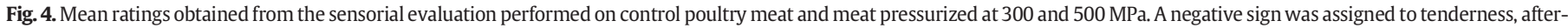

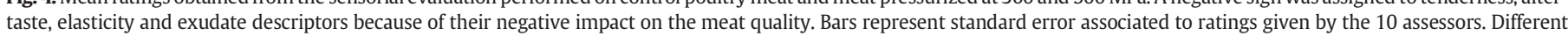
lowercase letters represent bars associated with significantly different mean ratings $(P<0.05)$. 
Table 4

Color measurements performed on control and treated poultry meat at 200, 300 and 400 $\mathrm{MPa}$, using the $\mathrm{L} \mathrm{a}^{*} \mathrm{~b}^{*}$ colorimetric system.

\begin{tabular}{llrl}
\hline & \multicolumn{1}{l}{$\mathrm{L}^{*}$} & \multicolumn{1}{c}{$\mathrm{a}^{*}$} & $\mathrm{~b}^{*}$ \\
\hline Control & $41.29 \pm 3.70^{\mathrm{a}}$ & $9.75 \pm 0.80^{\mathrm{c}}$ & $10.73 \pm 0.94^{\mathrm{d}}$ \\
$200 \mathrm{MPa}$ & $41.22 \pm 2.60^{\mathrm{a}}$ & $10.02 \pm 0.62^{\mathrm{c}}$ & $11.62 \pm 1.22^{\mathrm{d}}$ \\
$300 \mathrm{MPa}$ & $42.25 \pm 2.62^{\mathrm{a}}$ & $9.91 \pm 1.01^{\mathrm{c}}$ & $11.38 \pm 1.22^{\mathrm{d}}$ \\
$400 \mathrm{MPa}$ & $46.20 \pm 3.01^{\mathrm{b}}$ & $9.76 \pm 1.05^{\mathrm{c}}$ & $11.64 \pm 1.27^{\mathrm{d}}$ \\
\hline
\end{tabular}

Values represent mean measurements performed on 5 points and on duplicates on the surface of the meat. Bars represent the associated standard deviations. Different lowercase letters represent bars associated with significantly different mean values $(P<0.05)$.

its concentration was $1.5 \mathrm{log} \mathrm{cfu} / \mathrm{g}$ in unpressurized control (Table 5). The model-estimated the contamination level of $E$. coli in unpressurized samples to $1.69 \log \mathrm{cfu} / \mathrm{g}$ which is close to what was experimentally found. No E. coli could be detected in pressurized samples, with the detection limit of $1 \log \mathrm{cfu} / \mathrm{g}$ although the model had predicted that $13 \%$ of the contamination level should be between 1 and $2 \log \mathrm{cfu} / \mathrm{g}$ and thus detectable. However the number of batches analyzed, i.e. 6, did not enable to detect this fraction of the population of E. coli, pointing out sampling limitations. Anyway, $100.00 \%$ of the analyzed pressurized samples had a contamination level below $5000 \mathrm{cfu} / \mathrm{g}$, which meets the hygienic criterion.

Salmonella was not detected in any 25-g samples analyzed, pressurized or not, showing that its prevalence was below $3.3 \%$ and its concentration below $0.04 \mathrm{cfu} / \mathrm{g}$. The model-estimated prevalence in $25 \mathrm{~g}$ was $0.64 \%$ for pressurized and $11.7 \%$ for unpressurized samples. However in both cases, $100.00 \%$ of the contamination level was model-estimated below the experimental limit of $0.04 \mathrm{cfu} / \mathrm{g}$. Again, considering the batches analyzed, the safety criterion associated with Salmonella was met.

Regarding L. monocytogenes, it was not detected in 25-g unpressurized samples after 15 days of storage although the prevalence was model-estimated to $16.8 \%$. Nevertheless, it is in agreement with the model prediction since $99.99 \%$ of the population was estimated to be below the experimental detection limit of $0.04 \mathrm{cfu} / \mathrm{g}$. On the other hand, $L$. monocytogenes was detected after 22 days of storage in two pressurized batches out of 6 at a concentration below $1 \log \mathrm{cfu} / \mathrm{g}$. For the first batch, it was found in 2 samples out of 5 and in the second one, in 1 out of 5 , resulting in a prevalence of $10 \%$ ( 3 out of 30 samples), which is higher than that calculated from the probabilistic model $(1.1 \%$

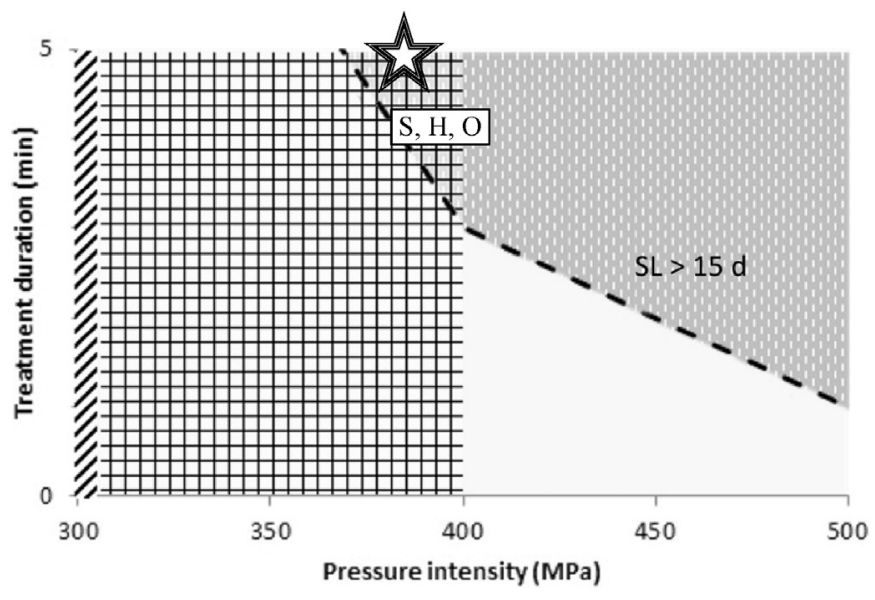

Fig. 5. Final operational window defined by superimposition of hygienic, safety and organoleptic criteria for a shelf-life (SL) equal or above 15 days during a chilled storage sequentially at $4{ }^{\circ} \mathrm{C}$ for $2 / 3 \mathrm{SL}$ and $8{ }^{\circ} \mathrm{C}$ for $1 / 3 \mathrm{SL}$ in presence of $1.8 \%(w / w)$ lactate. The checkered area inside the rectangle defines the operational window regarding the organoleptic criteria. The areas above the dashed line define the operational windows regarding hygienic criteria ( $\mathrm{SL}>15$ days). The star represents the HP treatment to be tested and validated. S, H, O: Area in which hygienic, safety and organoleptic criteria are met for $\mathrm{SL}<15$ days. with a probability of $98.86 \%$ that the contamination level is below $1 \log \mathrm{cfu} / \mathrm{g}$ ). With a similar model-estimated distribution, $L$. monocytogenes was however not detected after 20 days of chilled storage. It shows that sampling plays an important role when prevalence and contamination levels are expected to be low. Lastly, with a concentration below $1 \log \mathrm{cfu} / \mathrm{g}$ and a fortiori below $2 \log \mathrm{cfu} / \mathrm{g}$, the safety criteria associated with $L$. monocytogenes was also fulfilled following this treatment.

Concerning the additional criterion associated with LAB, despite one week later enumeration, the concentration of LAB was still two-log lower than the 7.0-log maximum concentration already reached in the control after 15 days of storage. This complies with the FCD criteria.

Considering the organoleptic criteria, overall, tenderness, juiciness and elasticity descriptors were found to be altered by HHP as previously expected (Table 5). In contrast, another descriptor associated to aftertaste was shown to be significantly altered following HHP. In fact, an acidic after-taste due to high concentration of lactic acid produced by LAB was perceived in unpressurized samples. Lastly, although the pressure intensity was below $400 \mathrm{MPa}$, the judges still found a difference between treated and untreated samples regarding raw appearance, mainly due to color modification $(P<0.05)$.

\section{Discussion}

For the microbiological part, quantitative exposure assessment models were developed and/or re-used to determine the contamination level of selected safety and hygienic microorganisms from raw materials to the end of the end-product shelf-life. The exposure assessment of the safety indicators, i.e. L. monocytogenes and Salmonella, was performed by running a probabilistic model previously developed (Lerasle et al., 2014). Among these two pathogens the only one which significantly conditioned shelf-life extension was L. monocytogenes.

The exposure assessment of $E$. coli was performed by developing a probabilistic model with the same modular structure as for the safety indicators. E. coli inactivation by HHP was modeled with log linear model with tail. Although Weibull model is widely used for HHP-induced microbial inactivation (Buzrul et al., 2005; Chen and Hoover, 2004), it was shown that the former provided the best fit, as previously observed by Hereu et al. (2012) for modeling HHP-inactivation of $L$. monocytogenes in RTE products. The occurrence of tails has been frequently reported in the literature (Diels et al., 2007) and has been related to heterogeneity of the pressure resistance within a microbial population. In the secondary modeling, the $\log \left(\mathrm{N}_{\text {res }}\right)$ value towards which the contamination level tends as treatment duration increases, was shown not to significantly depend upon pressure intensity. Hence, the size of the 'resistant' population seems to be of approximately $2 \log$ whatever the pressure between 300 and $500 \mathrm{MPa}$. On the contrary, the log-transformation of the inactivation rate $\mathrm{k}_{\max }$ was shown to increase with pressure intensity. Although E. coli is generally recognized as a microorganism sensitive to pressure with a reduction of 4.5-log after application of $400 \mathrm{MPa}$ during $10 \mathrm{~min}$ in model meat (Garriga et al., 2002) or total inactivation of $4 \mathrm{log}$ following application of $600 \mathrm{MPa}$ for $6 \mathrm{~min}$ in cooked ham and marinated beef (Jofré et al., 2009), some strains are shown to be rather baroresistant like a strain of the serotype 0157:H7 in ground beef which was only inactivated by $2.45 \mathrm{log} \mathrm{cfu} / \mathrm{g}$ after a treatment of $400 \mathrm{MPa}$ at $12{ }^{\circ} \mathrm{C}$ for $20 \mathrm{~min}$ (Morales et al., 2008). With hardly 3 log inactivated following application of $400 \mathrm{MPa}$ during $10 \mathrm{~min}$, the cocktail of $E$. coli strains of the present study seemed also to be rather resistant. However the comparison of inactivation rates among different HHP studies is difficult because of variations in strain resistance, food composition, processing conditions (Diels et al., 2007). Nevertheless, the fact that these strains were harvested on the production site of the minced meat makes their selection relevant. Regarding the inactivation parameters, the comparison with other models including Weibull is possible since decimal reduction time, $\mathrm{D}$, and $\mathrm{Z}_{\mathrm{HP}}$ values can be calculated from $\mathrm{k}_{\max }$ (Eq. (1)) and the 
Table 5

Microbiological determination and sensorial evaluation for validation of a shelf-life of 22 days for a product containing $1.8 \%$ lactate pressurized at 370 MPa during 5 min.

\begin{tabular}{|c|c|c|c|c|c|c|}
\hline \multirow{2}{*}{$\begin{array}{l}\text { Samples } \\
\text { Storage duration }\end{array}$} & & & \multirow{2}{*}{$\frac{\text { Unpressurized control }}{15 \text { days }}$} & \multicolumn{3}{|c|}{ Pressurized at $370 \mathrm{MPa}-5 \mathrm{~min}$} \\
\hline & & & & 15 days & 20 days & 22 days \\
\hline \multirow{2}{*}{ Hygienic indicator } & \multirow{2}{*}{ E. coli } & Prevalence $^{\mathrm{a}}$ & $100 \%$ & $<3.3 \%$ & $<3.3 \%$ & $<3.3 \%$ \\
\hline & & $\log \mathrm{cfu} / \mathrm{g}^{\mathrm{b}}$ & $1.5 \pm 0.3$ & $<1$ & $<1$ & $<1$ \\
\hline \multirow[t]{4}{*}{ Safety indicators } & \multirow[t]{2}{*}{ Salmonella } & Prevalence $^{\mathrm{a}}$ & $<3.3 \%$ & $<3.3 \%$ & $<3.3 \%$ & $<3.3 \%$ \\
\hline & & $\log \mathrm{cfu} / \mathrm{g}^{\mathrm{b}}$ & $<-1.4$ & $<-1.4$ & $<-1.4$ & $<-1.4$ \\
\hline & \multirow[t]{2}{*}{ L. monocytogenes } & Prevalence $^{\mathrm{a}}$ & $<3.3 \%$ & $<3.3 \%$ & $<3.3 \%$ & $10 \%$ \\
\hline & & $\log \mathrm{cfu} / \mathrm{g}^{\mathrm{b}}$ & $<-1.4$ & $<-1.4$ & $<-1.4$ & $<1$ \\
\hline FCD criterion & Lactic acid bacteria & $\log \mathrm{cfu} / \mathrm{g}^{\mathrm{b}}$ & $7.1 \pm 0.4$ & $5.0 \pm 0.1$ & $5.7 \pm 0.9$ & $6.1 \pm 0.5$ \\
\hline \multirow[t]{11}{*}{ Organoleptic indicators $^{c}$} & Odor intensity & \multirow[t]{11}{*}{ Mean rating \pm sd } & $5.39 \pm 2.27$ & ND & $5.65 \pm 1.34$ & ND \\
\hline & Taste intensity & & $5.43 \pm 2.34$ & ND & $5.83 \pm 1.56$ & ND \\
\hline & Saltiness & & $5.27 \pm 1.96$ & ND & $5.26 \pm 1.60$ & ND \\
\hline & After-taste & & $-5.13 \pm 2.70^{\mathrm{A}}$ & ND & $-2.7 \pm 2.08^{\mathrm{B}}$ & ND \\
\hline & Tenderness & & $5.52 \pm 1.65^{\mathrm{A}}$ & ND & $6.96 \pm 1.92^{\mathrm{B}}$ & ND \\
\hline & Elasticity & & $-5.39 \pm 1.92$ & ND & $-4.74 \pm 1.81$ & ND \\
\hline & Exudate & & $-3.04 \pm 2.03$ & ND & $-3.26 \pm 2.07$ & ND \\
\hline & Juiciness & & $4.83 \pm 1.64$ & ND & $6.22 \pm 1.24$ & ND \\
\hline & Raw appearance & & $6.74 \pm 1.01^{\mathrm{B}}$ & ND & $3.48 \pm 1.56^{\mathrm{A}}$ & ND \\
\hline & Cooked appearance & & $5.59 \pm 1.94$ & ND & $5.78 \pm 1.35$ & ND \\
\hline & Acceptance & & $4.43 \pm 1.50^{\mathrm{A}}$ & ND & $5.96 \pm 1.40^{\mathrm{B}}$ & ND \\
\hline
\end{tabular}

ND: Not Determined.

a $3.3 \%$ represents the limit of detection for prevalence.

b Mean microbial concentration with standard deviation obtained from 6 batches, with 5 replicates in each. 1 log cfu/g is the limit of detection for E. coli, Salmonella and L. monocytogenes concentration, when $<1 \mathrm{cfu}$ was enumerated and $-1.4 \mathrm{log} \mathrm{cfu} / \mathrm{g}$ in case of absence in $25 \mathrm{~g}$.

c A negative sign was assigned to tenderness, after-taste, elasticity and exudate descriptors because of their negative impact on the meat quality. Standard errors associated to ratings given by the 23 assessors are given. Different uppercase letters represent mean ratings associated with significantly different mean ratings $(P<0.01)$.

slope a in Eq. (2). $Z_{\mathrm{HP}}$ was found to be $170 \mathrm{MPa}$. However, few E. coli HHP-inactivation curves have been modeled to enable comparisons. Noma et al. (2002) have found $Z_{\mathrm{HP}}$ of 113 to 129 and 93.8 to $96.6 \mathrm{MPa}$ for $E$. coli K12 and IFO 3942 in $0.9 \%(w / v)$ sodium chloride solution for treatments performed at $5{ }^{\circ} \mathrm{C}$ to $25^{\circ} \mathrm{C}$. $\mathrm{Z}_{\mathrm{HP}}$ could also be evaluated to $212 \mathrm{MPa}$ at 10 and $20^{\circ} \mathrm{C}$ in freshly extracted carrot juices (Van Opstal et al., 2005). Finally, the $Z_{\mathrm{HP}}$ value that we have found was in the range of what is generally found in the literature. Then, following inactivation of $E$. coli induced by HHP treatment, it appeared that regrowth or recovery did not occur except occasionally after 300-MPa treatments. Inhibition of the recovery of $E$. coli during chilled storage in meat products was also shown by Jofré et al. (2009). After immediate lethal effect of pressurization, the contamination levels of some micro-organisms such as E. coli were shown to remain constant, underlying their inability to recover following HHP. The authors suggested that the intrinsic properties of the food might play an important role by enabling bacteria to grow or by creating additional hurdles incompatible with regrowth. The purpose of the study was also to consider the role of lactate in shelf-life extension in order to eventually remove it from the current formulation. Whether lactate was added or not at $1.8 \%$, E. coli was equally inactivated and no regrowth was observed during chilled storage. Consequently E. coli criterion was considered not to be a limiting factor for lactate removal in the current formulation. In contrast, Masana et al. (2015) observed that lactate added at a higher concentration, i.e. $3 \%$, could provide some protective action by reducing the number of $E$. coli STEC injured cells in fresh carpaccio. Moreover significant inhibitory effect of lactate on E. coli growth has already been observed in other studies (Hwang and Juneja, 2011). However the choice of keeping lactate in the product formulation was made since a shelf-life extension of one week could not be achieved in absence of lactate because of $L$. monocytogenes growth.

From the organoleptic side, the main adverse effect of high pressure on the organoleptic quality was shown to be the color lightening which compromised the product acceptance. Indeed color appeared to be one of the characteristics that affects consumer acceptance among lipid and protein oxidation (Rubio et al., 2007), modification of water retention (Korzeniowski et al., 1999) and texture (Chattong and Apichartsrangkoon, 2009), or development of aroma and taste components (Schindler et al., 2010). An increase of the colorimetric L* component associated to lightening was observed following HHP and especially for pressures above $400 \mathrm{MPa}$. Although this is most documented for red meat, it has also been observed in poultry meat from 300 MPa (Beltran et al., 2004; Del Olmo et al., 2010; Kruk et al., 2011; Tintchev et al., 2010). This lightening effect has been attributed to myoglobin denaturation or oxidation and/or to heme displacement or release, at or above $400 \mathrm{MPa}$ (Carlez et al., 1995), or to protein coagulation with a resulting loss of solubility of sarcoplasmic and/or myofibrillar proteins (Goutefongea et al., 1995).

Considering the validation of the framework, regarding safety aspects, Salmonella was found absent in $25 \mathrm{~g}$, i.e. with a contamination level below $0.04 \mathrm{cfu} / \mathrm{g}$, even in unpressurized analyzed controls. Concerning L. monocytogenes, it was detected in pressurized samples after 22 days of storage with a prevalence of $10 \%$, namely, higher than expected through modeling, but surprisingly not found after 20 days of storage. Still, the contamination level regarding L. monocytogenes at the end of the shelf-life was also satisfactory regarding the safety criteria.

Regarding the hygienic indicator, E. coli was undetected in pressurized samples after 22 days of chilled storage and a fortiori below $5000 \mathrm{cfu} / \mathrm{g}$, which also fulfills the hygienic criterion.

When prevalence and/or contamination levels were very low, limitation of the sampling method made it impossible to really compare model contamination level outputs with the experimentally enumerated populations. However this was not the aim of the validation of the framework. The purpose of this validation was to determine if all criteria were fulfilled and this was indeed achieved regarding safety and hygienic criteria. From the side of the additional hygienic criterion associated with LAB, HHP was shown to partially inactivate the LAB population but regrowth definitely occurred during chilled storage. Nevertheless their concentration was still below 7 log after 22 days of storage. The ability of LAB to recover from HHP has already been observed (Patterson et al., 2010). Jofré et al. (2009) even showed that despite the initial microbial reduction induced by HHP, LAB could close the gap during chilled storage and reach the same contamination level as in unpressurized samples. Fortunately, this was not observed in our experiments. Consequently, all microbiological criteria were considered as satisfying for extending the product shelf-life by one week. Considering organoleptic aspects, high pressure was also shown to affect some other 
sensorial descriptors but generally in a positive way. For instance, pressurized products were found to be less elastic, juicier and tenderer. The influence of high pressure on texture attributes of meat has already been observed. Indeed Mor-Mur and Yuste (2003) and Yuste et al. (1999) found that pressurized sausages became more cohesive and less firm or hard than heat-treated ones. Moreover from triangle tests, a preference was given to pressurized products particularly for their juicier texture (Mor-Mur and Yuste, 2003). In our experiments, the result regarding product acceptance was also in favor of pressurized products because the cooking step previous to product display, enabled to rule out the negative impact of color lightening. Contrary to what was observed by Rubio et al. (2007) for some pressurized products, no anomalous odor and taste, has developed during chilled storage which would have impaired shelf-life extension. Moreover, by delaying growth of LAB during chilled storage, HHP was shown to be able to reduce the acidic after-taste due to accumulation of lactate produced from LAB metabolism. The only drawback was the color alteration. Indeed, it has been recognized that the color change constitutes the major bottleneck in application of HHP to raw products. Several attempts could be explored to try to overstep it. For instance, improvements of HHP might be brought by lowering the temperature during treatment, for example at subzero temperature (Fernandez et al., 2007; Vaudagna et al., 2012), by using opaque vacuum packaging, or making grill marks on raw products. Considering that there are means to improve raw appearance and that color alteration is no longer a concern since the product is consumed cooked, it was then concluded that the organoleptic criterion was also fulfilled. Consequently, it was found that the selected HHP treatment could enable the extension of the shelf-life by one week, hence validating the multi-criteria framework.

In conclusion, a risk-risk tradeoff associated with probabilistic models was used to determine the shelf-life of poultry products. The added value of this study is the establishment of a framework including criteria from different fields that food processors have to comply with since they have to determine the shelf-life of new products or products with a modified processing step. This approach is innovative because it does not prioritize one aspect rather than another. Each step associated with one criterion should result in a decision, namely an operational window that restricts the treatment parameters within some values enabling to fulfill the criterion. The approach developed in this study represents a valuable decision support tool for shelf-life determination as it encompasses both safety and quality criteria, and enables to move to more quantitative, objective and transparent approaches.

Supplementary data to this article can be found online at http://dx doi.org/10.1016/j.ijfoodmicro.2016.05.027.

\section{References}

AFNOR, 2010. NF V01-003 - Food Safety - Guidelines for the Drawing up of Durability Studies - Chilled Perishable and highly Perishable Foodstuffs.

Beltran, E., Pla, R., Capellas, M., Yuste, J., Mor-Mur, M., 2004. Lipid oxidation and colour in pressure- and heat-treated minced chicken thighs. J. Sci. Food Agric. 84, 1285-1289.

Buzrul, S., Alpas, H., Bozoglu, F., 2005. Use of Weibull frequency distribution model to describe the inactivation of Alicyclobacillus acidoterrestris by high pressure at different temperatures. Food Res. Int. 38, 151-157.

Carlez, A., Veciana-Nogues, T., Cheftel, J.-C., 1995. Changes in colour and myoglobin of minced beef meat due to high pressure processing. Lebensm.-Wiss. Technol. 28 528-538.

CCFRA, 1977. Guidelines for the Establishment of Scheduled Heat Processes for Low Acid Canned Foods. Technical Manual No.3. Campden and Chorleywood Food Research Association, Chiping Campden, UK.

Chattong, U., Apichartsrangkoon, A., 2009. Dynamic viscoelastic characterisation of ostrich-meat yor (Thai sausage) following pressure, temperature and holding time regimes. Meat Sci. 81, 426-432.

Chen, H., Hoover, D.G., 2004. Use of Weibull model to describe and predict pressure inactivation of Listeria monocytogenes Scott a in whole milk. Innovative Food Sci. Emerg. Technol. 5, 269-276.

Del Olmo, A., Morales, P., Ávila, M., Calzada, J., Nuñez, M., 2010. Effect of single-cycle and multiple-cycle high-pressure treatments on the colour and texture of chicken breast fillets. Innovative Food Sci. Emerg. Technol. 11, 441-444.
Delignette-Muller, M.-L., Pouillot, R., Denis, J.-B., Dutang, C., 2014. Fitdistrplus: help to fit of a parametric distribution to non-censored or censored data. (Available Online) http://cran.at.r-project.org/web/packages/fitdistrplus/fitdistrplus.pdf.

Diels, A., Van Opstal, I., Masschalck, B., Michiels, C.W., 2007. Modelling of high-pressure inactivation of microorganisms in foods. In: Brul, S., Van Gerwen, S., Zwietering M. (Eds.), Modelling Microorganisms in Food. Woodhead Publishing Limited and CRC Press LLC, Washington, DC, pp. 161-197.

FAO/WHO 2004. Food safety and quality in Europe: aspects concerning in particular quality, nutritional balance, the importance of agricultural land and cultural heritage ("Terroirs"). 24th FAO Regional Conference for Europe, Montpellier, France.

Fernandez, A., Lopez, M., Bernardo, A., Condon, S., Raso, J., 2007. Modelling thermal inactivation of Listeria monocytogenes in sucrose solutions of various water activities. Food Microbiol. 24, 372-379.

Garriga, M., Aymerich, M.T., Costa, S., Monfort, J.M., Hugas, M., 2002. Bactericidal synergism through bacteriocins and high pressure in a meat model system during storage. Food Microbiol. 19, 509-518.

Goutefongea, R., Rampon, V., Nicolas, J., Dumont, J., 1995. Meat color changes under high pressure treatment. Proceeding of the 41st International Congress of Meat Science and Technology, San Antonio, Texas, pp. 384-385.

Hayman, M.M., Baxter, I., O'Riordan, P.J., Stewart, C.M., 2004. Effects of high-pressure processing on the safety, quality, and shelf life of ready-to-eat meats. J. Food Prot. 67, 1709-1718.

Hereu, A., Dalgaard, P., Garriga, M., Aymerich, T., Bover-Cid, S., 2012. Modeling the high pressure inactivation kinetics of Listeria monocytogenes on RTE cooked meat products. Innovative Food Sci. Emerg. Technol. 16, 305-315.

Heymann, H., Machado, B., Torri, L., Robinson, A.L., 2012. How many judges should one use for sensory descriptive analysis? J. Sens. Stud. 27, 111-122.

Hunter, P.R., Fewtrell, L., 2001. Acceptable risk. In: Fewtrell, L., Bartram, J. (Eds.), Water Quality: Guidelines, Standards and Health, Vol. Chapter 10. IWA Publishing, London, UK, pp. 208-227.

Hwang, C.A., Juneja, V., 2011. Effects of salt, sodium pyrophosphate, and sodium lactate on the probability of growth of Escherichia coli 0157:H7 in ground beef. J. Food Prot. 74, 622-626.

ICMSF, 2002. Microorganisms in Foods 7, Microbiological Testing in Food Safety Management. Kluwer Academic/Plenum Publishers, New York.

ISO, 2004. International Organization for Standardization. Sensory Analysis - Methodology - Triangle Test (ISO 4120).

Jofré, A., Aymerich, T., Grèbol, N., Garriga, M., 2009. Efficiency of high hydrostatic pressure at $600 \mathrm{MPa}$ against food-borne microorganisms by challenge tests on convenience meat products. Lebensm.-Wiss. Technol. 42, 924-928.

Korzeniowski, W., Jankowska, B., Kwiatkowska, A., 1999. The effect of high pressure on some technological properties of pork. Electron. J. Pol. Agric. Univ. Food Sci. Technol. 2.

Kruk, Z.A., Yun, H., Rutley, D.L., Lee, E.J., Kim, Y.J., Jo, C., 2011. The effect of high pressure on microbial population, meat quality and sensory characteristics of chicken breast fillet. Food Control 22, 6-12.

Lerasle, M., Guillou, S., Simonin, H., Anthoine, V., Chéret, R., Federighi, M., Membré, J.M., 2014. Assessment of Salmonella and Listeria monocytogenes level in ready-to-cook poultry meat: Effect of various high pressure treatments and potassium lactate concentrations. Int. J. Food Microbiol. 186, 74-83.

Lin, M., Al-Holy, M., Mousavi-Hesary, M., Al-Qadiri, H., Cavinato, A.G., Rasco, B.A., 2004. Rapid and quantitative detection of the microbial spoilage in chicken meat by diffuse reflectance spectroscopy (600-1100 nm). Lett. Appl. Microbiol. 39, 148-155.

Mantilla, S.P., Santos, E.B., de Freitas, M.Q., de Carvalho Vital, H., Mano, S.B., Franc, R.M., 2012. Refrigerated poultry breast fillets packed in modified atmosphere and irradiated: Bacteriological evaluation, shelf life and sensory acceptance. Braz. J. Microbiol. 43, $1385-1393$.

Masana, M.O., Barrio, Y.X., Palladino, P.M., Sancho, A.M., Vaudagna, S.R., 2015. High pressure treatments combined with sodium lactate to inactivate Escherichia coli 0157:H7 and spoilage microbiota in cured beef carpaccio. Food Microbiol. 46, 610-617.

Morales, P., Calzada, J., Avila, M., Nunez, M., 2008. Inactivation of Escherichia coli 0157: H7 in ground beef by single-cycle and multiple-cycle high-pressure treatments. J. Food Prot. 71, 811-815

Mor-Mur, M., Yuste, J., 2003. High pressure processing applied to cooked sausage manufacture: Physical properties and sensory analysis. Meat Sci. 65, 1187-1191.

Noma, S., Shimoda, M., Hayakawa, I., 2002. Inactivation of vegetative bacteria by rapid decompression treatment. J. Food Sci. 67, 3408-3411.

Patterson, M.F., 2005. Microbiology of pressure-treated foods. J. Appl. Microbiol. 98, $1400-1409$

Patterson, M.F., McKay, A.M., Connolly, M., Linton, M., 2010. Effect of high pressure on the microbiological quality of cooked chicken during storage at normal and abuse refrigeration temperatures. Food Microbiol. 27, 266-273.

Pereira, J.A., Silva, P., Matos, T.J., Patarata, L., 2015. Shelf life determination of sliced Portuguese traditional blood sausage-Morcela de Arroz de Monchique through microbiological challenge and consumer test. J. Food Sci. 80, M642-M648.

Pujol, L., Kan-King-Yu, D., Le Marc, Y., Johnston, M.D., Rama-Heuzard, F., Guillou, S., McClure, P., Membré, J.-M., 2012. Establishing equivalence for microbial-growth-inhibitory effects ("Isohurdle rules") by analyzing disparate Listeria monocytogenes data with a gamma-type predictive model. Appl. Environ. Microbiol. 78, 1069-1080.

Rosso, L., 1995. Modelling and Predictive Microbiology: Elaboration of a New Tool for the Food Industry. Université Claude Bernard Lyon I, Lyon.

Rubio, B., Martínez, B., García-Cachán, M.D., Rovira, J., Jaime, I., 2007. Effect of high pressure preservation on the quality of dry cured beef "Cecina de Leon". Innovative Food Sci. Emerg. Technol. 8, 102-110.

Ruzante, J.M., Davidson, V.J., Caswell, J., Fazil, A., Cranfield, J.A., Henson, S.J., Anders, S.M., Schmidt, C., Farber, J.M., 2010. A multifactorial risk prioritization framework for foodborne pathogens. Risk Anal. 30, 724-742. 
Schindler, S., Krings, U., Berger, R.G., Orlien, V., 2010. Aroma development in high pressure treated beef and chicken meat compared to raw and heat treated. Meat Sci. 86, 317-323.

Simonin, H., Duranton, F., de Lamballerie, M., 2012. New insights into the high-pressure processing of meat and meat products. Compr. Rev. Food Sci. Food Saf. 11, 285-306.

Tintchev, F., Wackerbarth, H., Kuhlmann, U., Toepfl, S., Knorr, D., Hildebrandt, P., Heinz, V., 2010. Molecular effects of high-pressure processing on food studied by resonance Raman. Ann. N. Y. Acad. Sci. 1189, 34-42.

Van Derlinden, E., Bernaerts, K., Van Impe, J.F., 2008. Accurate estimation of cardinal growth temperatures of Escherichia coli from optimal dynamic experiments. Int. J. Food Microbiol. 128, 89-100.
Van Opstal, I., Vanmuysen, S.C., Wuytack, E.Y., Masschalck, B., Michiels, C.W., 2005. Inactivation of Escherichia coli by high hydrostatic pressure at different temperatures in buffer and carrot juice. Int. J. Food Microbiol. 98, 179-191.

Vaudagna, S.R., Gonzalez, C.B., Guignon, B., Aparicio, C., Otero, L., Sanz, P.D., 2012. The effects of high hydrostatic pressure at subzero temperature on the quality of ready-toeat cured beef carpaccio. Meat Sci. 92, 575-581.

Vose, D., 2008. Risk Analysis: A Quantitative Guide. third ed. Wiley et Sons, Chichester. Wilcock, A., Pun, M., Khanona, J., Aung, M., 2004. Consumer attitudes, knowledge and behaviour: A review of food safety issues. Trends Food Sci. Technol. 15, 56-66.

Yuste, J., Mor-Mur, M., Capellas, M., Guamis, B., Pla, R., 1999. Mechanically recovered poultry meat sausages manufactured with high hydrostatic pressure. Poult. Sci. 78, 914-921. 